\title{
STRUCTURAL AND IMMUNOCYTOCHEMICAL ALTERATIONS IN EYE LENS FIBER CELLS FROM Cx46 AND Cx50 KNOCKOUT MICE
}

\author{
Irene Dunia ${ }^{*+}$, Christian Cibert $* *$, Xiaohua Gong ${ }^{\circ}$, Chun-hong Xia ${ }^{\circ}$, Michel Recouvreur*, \\ Essy Levy ${ }^{\circ}$, Nalin Kumar ${ }^{\circ \circ}$, Hans Bloemendal ***, and E. L. Benedetti*.
}

Biologie Cellulaire* and Morphométrie et Modélisation Cellulaire**, Institut Jacques Monod, CNRS, UMR 7592 Universités Paris 6 - Paris 7, Paris, France.

School of Optometry ${ }^{\circ}$, University of California, Berkeley, CA 94720, USA

Dpt. Cell Biology ${ }^{\circ}$, The Scripps Research Institute, La Jolla, CA 92037, USA

Dpt. Ophthalmology/Visual Sciences ${ }^{\circ \circ}$, Univ. of Illinois, Chicago, Illinois 60612, USA

Dpt. of Biochemistry***, Radboud University of Nijmegen, Nijmegen, The Netherlands

+ To whom correspondence should be addressed : Irène Dunia, Dpt. Biologie Cellulaire, Institut Jacques Monod, 2, place Jussieu, F-75251 Paris CEDEX 5, France.

Tel : 33144274223 ; Fax : 33144275994 ; Email : dunia@ijm.jussieu.fr

\begin{abstract}
In the current study we describe the changes of overall organization of lens fiber cells in connexin $46(\mathrm{Cx} 46)$ and connexin $50(\mathrm{Cx50})$ knockout mice. Morphometric analyses and the application of immunocytochemical techniques revealed that in $\mathrm{Cx} 46$ knockout lens (Cx46 -/-), where Cx50 is expressed alone, the post-natal differentiation of secondary fiber cells proceeds faster and is characterized by an increased number of smaller fiber cells. Conversely, in $\mathrm{Cx50}$ knockout mice ( $\mathrm{Cx50}$-/-), the lenticular mass is considerably reduced and characterized by a small number of fiber cells added during the post-natal period. The process of terminal differentiation was impaired and generated larger fiber cells still possessing cytoplasmic organelles. Freeze-fracture and fracture labeling revealed that the junctional assembly, packing organization and topographic interactions between connexons and MP26 differed when $\mathrm{Cx46}$ and $\mathrm{Cx50}$ were coassembled in the wild-type or expressed separately in the two distinct knockout phenotypes. Filipin cytochemistry provided indirect evidence that $\mathrm{Cx46}$ and $\mathrm{Cx50}$ expressed alone are recruited into different lipid environments. Our results represent the structural proof that interaction of connexins and MP26, contributes to the overall organization of the fiber cells.
\end{abstract}

Key words: Gap junction, morphometry, fracture-labeling, MP26, Aquaporin 0, Connexin 46, Connexin 50, cataract. 


\section{INTRODUCTION}

Cell-cell communication in the eye lens and circulation of ions and metabolites proceed throughout the anterior epithelial cell monolayer, differentiating (DF), mature (MF) and nuclear fiber cells (NF). These communicating compartments are connected by a gap junction network that is selectively regulated by coupling and gating modulators such as phosphorylation and proteolysis of the C-termini of the transmembrane channel forming polypeptides (Mathias et al., 1997 ; Mathias and Rae, 2004). In parallel to the functional diversity of the communicating compartments, different connexin isoforms are expressed in the lens. The epithelial gap junctions comprise mainly connexin 43 (Cx43) and during fiber cell differentiation these communication pathways are removed by internalization (Benedetti et al., 1996), assisted by proteasome degradation (Berthoud et al., 2000). New junctional domains are formed between DF plasma membranes by recruiting coexpressed Cx46 and Cx50 (Hertzberg et al., 1982 ; Kistler et al., 1990 ; White et al., 1995). These two connexins form connexon pairs characterized by a variable combination of the channel-forming polypeptides (heteromeric, heterotypic, homomeric, homotypic connexons) (Beahm and Hall, 2002 ; Jiang and Goodenough, 1996; Kumar and Gilula, 1996 ; Sosinsky, 1996). It is noteworthy that the association of $\mathrm{Cx} 46$ and $\mathrm{Cx} 50$ confers to the permeable channels, new cooperative functional features compared to the properties of the connexons formed by one or the other connexin alone (Beahm and Hall, 2002 ; Bruzzone et al., 1994 ; Ebihara et al., 1999 ; Hopperstad et al., 2000 ; Mathias et al., 1997 ; Mathias and Rae, 2004). Both connexins contribute about equally to the coupling conductance of DF junctions, but the presence of the uncleaved Cx50 confers to the connexons the ability to close in response to cytoplasmic acidification (Mathias et al., 1997, Mathias and Rae, 2004). Actually, in the deep cortical and nuclear compartments (MF-DF), where Cx46 and Cx50 are partially degraded by various classes of proteases, the communicating channels remain open but became insensitive to intracellular acidification (Mathias et al., 1997 ; Mathias and Rae, 2004). Consistent with the changes of connexin expression, coupling and gating features, the junctional domains display variable ultrastructural aspects identified by ultrathin sections and freeze-fracture (Benedetti et al., 1996 ; Kuszak, 1995). The junctional pleomorphism, visualized in different lens compartments, includes non-uniform thickness and tightness of the close membrane apposition (thick and /or thin pentalaminar profiles) and the variation of the packing organization of the junctional intramembranous particles visualized by freeze-fracture (Benedetti et al., 1996; Kuszak, 1995 ; Kuszak et al., 2004).

In newly assembled DF junctional domains, the $9 \mathrm{~nm}$ junctional particles form loosely nongeometrically-packed clusters, whereas in MF-NF, the membrane fracture faces are characterized by the presence of geometrically -packed arrays of 7-8 nm repeating subunits (Benedetti et al., 1996; Kuszak, 1995 ; Kuszak et al., 2004).

Fiber cell differentiation is also characterized by the expression of a $26 \mathrm{kDa}$ protein which becomes the major intrinsic membrane protein (MP26 or MIP) of the fiber cells. MP26 plays an important role in water transport (Aquaporin 0) and acts as adhesion protein (Benedetti, et al., 1996 ; Deen and van Os, 1998 ; Dunia et al., 1987 ; Dunia et al., 1998 ;Fotiadis et al., 2000 ; Palanivelu et al., 2006 ; Varadaraj et al., 1999).

A direct role of connexins in the control and maintenance of lens homeostasis and clarity became more apparent when the targeted disruption of lens connexin genes was generated by homologous recombination. Key experiments demonstrated that the deletion of either Cx46 or Cx50 was followed by two different abnormal phenotypes (Gong et al., 1997;Gong et al., 1998; White et al., 1998; White, 2002).

In homozygous Cx46 -/- lenses, a nuclear cataract developed early after birth associated with degradation and condensation of crystallins (Gong et al., 1997; Gong et al., 1998). Actually, during cataractogenesis, cysteine proteases of the papain family were activated in parallel 
with increased $\mathrm{Ca}+2$ influx-rate and a reduced outflow (Baruch et al., 2001; Gao et al., 2004). The targeted ablation of the Cx50 gene induced microphthalmia and a zonular pulverulent cataract (White et al., 1998). The reduction of the lenticular mass in Cx50 -/- lenses was correlated with the diminished number of fiber cells (White, 2002).

The genetic, biochemical and electrophysiological features of the abnormal phenotypes resulting from the knockout of either Cx46 or Cx50 have been already characterized (Baldo et al., 2001; Gao et al., 2004; Gong et al., 1997 ; Gong et al., 1998 ; Martinez-Wittinghan et al., 2003; Rong et al., 2002 ; White et al., 1998; White, 2002). However, comprehensive ultrastructural, immunocytochemical and morphometric analysis of lens abnormalities, resulting from knockout of Cx46 and Cx50 genes, was only preliminarily addressed (Gong et al., 1997; Rong et al., 2002, White et al., 1998). To fill this gap we have chosen the most straightforward experimental conditions, namely the targeted disruption of one or the other lens fiber connexins.

One aim of the present study is to extend our investigation on the overall structural organization of the fiber cells throughout the lens mass in the two knockout phenotypes in comparison with the wild-type. Another issue is the characterization of the structural and immunocytochemical organization of gap junctions in different communication compartments and to correlate these features with the electrophysiological analysis carried out previously by Gong et al., (1998) and Baldo et al., (2001).

Among other approaches we applied the fracture-labeling technique (FL) because this method enables high-resolution immunocytochemical analysis of the bi-dimensional topographic distribution and packing organization of connexins. In addition, FL enables the study of the topographic interactions between connexins and other constituents (ZO-1 and MP26) that may assist junctional assembly (Dunia et al., 1998; Dunia et al., 2001; Fujimoto et al., 1997; Nielsen et al., 2003). This issue is of particular relevance because previous investigations in wild-type mouse lenses have demonstrated that MP26 may assist the junctional assembly comprising Cx46 and Cx50 (Dunia et al., 1987, 1998, 2001). Furthermore, experimental evidence has been provided that interaction between MP26 and the fiber cell connexins plays a pivotal role in the overall organization of fiber cells and junctional domain distribution during differentiation and aging of the lens (Al-Ghoul et al., 2003; Shen-Lin et al., 1998; Shiels et al., 2000; Yu and Jiang, 2004; Yu et al., 2005). Hence, the Cx46 and Cx50 knockout phenotypes offer a suitable condition for the study of the topographic interaction of MP26 with one or another fiber cell connexin and the consequences of this specific association on the overall structural organization of the lens fiber cells.

Our observations demonstrate that post-mitotic terminal differentiation in Cx46 -/- lens, proceeds faster and generates an increased number of smaller fiber cells. Conversely, postnatal fiber differentiation in Cx50 -/- lens, is hindered and produces a reduced number of larger, non hexagonally-shaped cells characterized by an abortive degradation of cellular organelles. Furthermore, the targeted ablation of either $\mathrm{Cx} 46$ or $\mathrm{Cx} 50$ is followed by a different packing arrangement of connexons and by changes in the topographic interactions of connexins with MP26 and their close lipid environment.

\section{MATERIALS AND METHODS}

\section{Homozygous mice lacking $\mathrm{Cx} 46(\mathrm{Cx} 46-/-)$ and $\mathrm{Cx} 50$ (Cx50 -/-)}

Generation of Cx46 and Cx50 knockout mice have been described previously (Gong et al., 1997; Rong et al., 2002). The knockout mice used in this study had been maintained for more than 15 generations in the C57BLx129Sv mixed strain background characterized by the high incidence of the cataractous phenotype. Wild-type, heterozygous knockout and homozygous knockout mice were generated from intercross of heterozygous knockout mice. The lenses were isolated from these mice for the different experiments. The data were obtained from the 
examination of at least 10 mutants of different knockout mice at ages between 3 and 8 weeks. Mouse breeding and experimental procedures were based on animal protocol approved by Animal Care And Use Committee.

\section{Lens samples}

Eye lenses were physically dissected to obtain DF regions (around $40 \%$ of total lens weight, at the periphery) and MF, NF regions (the remaining $60 \%$ ). The samples from different lens regions were rapidly fixed or processed without fixation, immediately after dissection.

For cryosectioning, fixation was performed in cold methanol $\left(-20^{\circ} \mathrm{C}\right)$ for $30 \mathrm{~min}$, or in $3 \%$ $(\mathrm{v} / \mathrm{v})$ paraformaldehyde in $0.2 \mathrm{M}$ phosphate buffer, $\mathrm{pH} 7.4$, for $12 \mathrm{~h}$ at $4^{\circ} \mathrm{C}$. Fixed pieces of 3$5 \mathrm{~mm}$ were impregnated in $2.3 \mathrm{M}$ sucrose-phosphate buffer overnight, deposed onto specimen holders (Leica Microsystèmes S.A., Rueil, France) rapidly frozen and stored in liquid nitrogen.

Cryo-sections of $1-2 \mu \mathrm{m}$ were made at $-85^{\circ} \mathrm{C}$ with the Leica Ultracut UCT equipped with a Leica EM FCS cryoattachment (Leica Microsystèmes S.A., Rueil, France).

\section{Immunofluorescence Confocal Laser Scanning Microscopy}

Immunofluorescence Confocal Laser Scanning Microscopy was performed on cryosections of 1-2 $\mu \mathrm{m}$, as described in Dunia et al.,(1998).

\section{Antibodies used}

1) An affinity-purified rabbit polyclonal antibody that recognizes the native form of the major intrinsic membrane protein of the lens fibers, MP26 (Hertzberg et al., 1982), at 1:300.

2) A rabbit anti-MP26 antiserum produced against chloroform-methanol- isolated MP26 that recognizes the native protein and its proteolytic derivatives at 1:200 and 1:2,000 for immunoblots (Dunia et al., 1987).

3) Affinity-purified polyclonal antibodies directed against a synthetic peptide corresponding to a3 Cx46 amino acids $111-125$ (Cx46J peptide) (Gong et al., 1997 ; cf. Milks et al., 1988) at 1:200 and 1:2,000 for immunoblots.

4) A rabbit anti-Cx50 antiserum produced against a synthetic peptide corresponding to $\mathrm{Cx} 50$ amino acids $124-136$ (White et al., 1992) at 1:200 and 1:2,000 for immunoblots,

5) The 6-4-B2-C6, anti-MP70 monoclonal antibody, recognizing only the native Cx50 protein (Kistler et al., 1990), at 1:10.

6) Detection of endoplasmic reticulum remnants and nuclear envelopes by immunofluorescence was achieved with anti-KDEL monoclonal antibody at 1:200 (Stressgen Biotechnologies, Canada) and anti-lamin A/C specific antibodies (Buendia and Courvalin, 1997).

Secondary antibodies for immunofluorescence were affinity-purified rhodamine-labeled (TRITC) donkey antibodies directed against rabbit immunoglobulins and fluorescein-labeled (FITC) goat antibodies directed against mouse immunoglobulins (Jackson Laboratories). For immunogold labeling we used Protein A conjugated to 10 or $15 \mathrm{~nm}$ gold particles (Cell Biology Department, University of Utrecht, The Netherlands).

\section{SDS-PAGE and Immunoblotting}

DF and MF-NF membrane fractions were processed for sodium dodecyl sulfate polyacrylamide gel electrophoresis (SDS-PAGE) as described elsewhere (Dunia et al., 1998). Briefly, cortical and nuclear lens regions separated by dissection and pooled from several lenses were homogenized in $40 \mathrm{mM} \mathrm{KCl}, 2 \mathrm{mM} \mathrm{MgCl}$ and $50 \mathrm{mM}$ Tris- $\mathrm{HCl}$, pH 7.5 (TKM buffer), containing $2 \mathrm{mM}$ phenylmethylsulfonyl fluoride at $4{ }^{\circ} \mathrm{C}$. Following two washes in TKM buffer, the membrane fractions obtained by centrifugation at 3,000 g for 10 minutes 
were subsequently treated with $4 \mathrm{M}$ urea for 15 minutes. The urea-insoluble pellets were collected by centrifugation at 50,000 g for 20 minutes and processed for 1à and $13 \%$ SDSPAGE. Proteins separated by SDS-PAGE were transferred onto nitrocellulose paper and incubated with the primary antibodies as described elsewhere (Dunia et al., 1998). Horseradish peroxidase-labeled goat anti-rabbit IgG was used as secondary antibody (Promega, Madison, WI/USA) Enhanced detection by chemiluminescence was performed using an ECL kit (Amersham International, Buckinghamshire/England).

\section{Electron Microscopy}

For thin sections, lens samples were processed as described previously (Dunia et al.,1998).

For freeze-fracture (FF) and fracture-labeling (FL) the samples were rapidly frozen in liquid propane, replicated and immunogold labeled as described by Dunia et al., (2001).

For filipin cytochemistry DF and MF-NF lens regions were processed according to the method developed by Orci et al., (1981). Briefly, small fragments of the glutaraldehyde-fixed samples were incubated overnight, in the dark, at room temperature, in a solution containing $0.2 \mathrm{mg} / \mathrm{ml}$ of filipin in $0.1 \mathrm{M}$ cacodylate buffer ( $\mathrm{pH}$ 7.4). Subsequently, samples were washed in cacodylate buffer and soaked in $30 \%$ glycerol in the same buffer before freeze-fracture experiments.

Thin sections and replicas were examined with a Philips CM12 and a TECNAI 12 (FEI, France) electron microscope operating at $80 \mathrm{kV}$. Images were recorded on photographic plates. All measurements of the packing arrangement of IMP and Fourier transforms of selected areas of the lattice organization, were done with the ImageJ software (Rasband, W.S., ImageJ, U. S. National Institute of Health, Bethesda, Maryland, USA, http://rsb.info.nih.gov/ij/, 1997-2006).

\section{Morphometric analysis and Modeling}

We modeled and calculated fiber cell dimensions and number of fibers within lens regions. The dedicated program was written under the C-interpreter of Visilog 4.1.1 (Noesis, France), installed on an Indigo 4000 entry work station (Silicon Graphics, USA).

Fiber cells were modeled accounting their topologies as described elsewhere (Kuszak and Costello, 2002; Kuszak et al., 2004). The lens is asymmetric and constituted by two ellipsoidal halves. The longest peripheral fibers link sutures that design a "Y" on frontal and backside poles of the lens. In Figure 1, these anterior and posterior suture lines are outlined in white and red colors, respectively. Their dimensions are defined by two cones, centered at the lens center, whose angles are $45^{\circ}$ and $30^{\circ}$, respectively. We considered 11 superficial lines calculated as the intersection between the circles corresponding to the boundaries of the respective series of frontal cross sections and two parables insuring their insertion within the two sutures (Figures 1A and IB). To measure the geometrical characteristics of the fibers, we delineated automatically the cross sections from a DF wild type thin section image (Figures 2A -2D). The main and transversal axes of the binary mask axes for each cross section were determined by measuring their Feret diameters (Coster and Cherman 1985) and calculated as functions of their area and eccentricity. Mask area and eccentricity were directly determined using the second order moments and mask orientation was calculated using the inertia matrix (Belaid and Belaid, 1992 ; Jahne, 1993). To measure Feret diameters of each binary mask, the masks were rotated within the image plane around their center of mass. The two perpendicular major and minor axes of the mask equivalent ellipse are outlined on Figure 2D, by green double arrows. The vertical Feret diameters $(\mathrm{V})$ and $(\mathrm{H})$ are more significant for the shape of the cross sections of the fibers because of the arc that they draw in the image plan. To calculate the number of fibers $(\mathrm{N})$ within a lens stratum (where the cell population is more 
homogeneous) we take into account the thickness of the stratum and the hexagonal fiber shape, The number of fibers $\mathrm{N}$ is given by the following equation:

$N=\frac{1}{2} \sum_{n=0}^{\frac{r}{2}} \frac{2 \pi\left(R_{2}-n \frac{r}{2}\right)}{\left(T-\frac{r}{2}\right)}$

$\mathrm{R}_{1}$ and $\mathrm{R}_{2}$ are the internal and external equatorial radius of the section of the stratum, $\mathrm{T}$ the tangential fiber length, $r$ the radial fiber length, and $n$ the rank of fiber cell layer within the stratum. $\mathrm{T}$ and $\mathrm{r}$ were deduced from the values of $\mathrm{V}$ and $\mathrm{H}$ calculated before as a function of the hexagonal fiber shape.

\section{Three-dimensional cell shape factor}

Modeling the structure of the longest superficial fibers, linking the anterior and posterior suture lines, we calculated: 1) The tangential profile of a fiber assimilated to an ellipse, whose major axis equals the fiber length and minor axis equals the value of $\mathrm{T}$.

2) The fiber thickness ( $r$ ). Measuring the surface/volume ratio was used as a means to quantify the fiber form (White et al., 1998). However, this ratio varies mainly according to the inverse of the radius of the fiber-equivalent sphere. Alternatively, we calculate a threedimensional cell shape factor $(\mathrm{R})$, presenting higher robustness:

$\mathrm{R}=\mathrm{S}^{3} / 26 \pi \mathrm{V}^{2}$

$\mathrm{S}$ is the fiber area and $\mathrm{V}$ the fiber volume.

This three-dimensional cell shape factor is a value without dimension that equals 1 for a sphere (whatever size it may have), and increases as the shape becomes different from a sphere, either due to deformation or to the increase of surface complexity (a similar factor is described in planar morphometry, Belaid and Belaid, 1992). We calculated this factor for fibers located within the $150 \mu \mathrm{m}$-width superficial lens layers. Measurements were performed on sections made on a frontal equatorial plane, for the three types of mice.

\section{Chemicals}

Unless otherwise indicated, all chemicals used for this work were purchased from Sigma Chemicals Co. (St Louis Mo/USA).

\section{RESULTS}

\section{SDS-PAGE and Immunoblotting}

Figure 3 shows the immunoblot experiments of DF and MF-NF membrane fractions of wildtype, Cx46 -/- and Cx50 -/- lenses.

DF membrane fraction of wild-type (Figure 3A, lane 1) shows prominent bands around 66 $\mathrm{kD}$ and $38 \mathrm{kD}$. DF membrane fraction of Cx46 -/- lens (Figure 3A, lane 3) is characterized by a weaker band around $66 \mathrm{kD}$ (compared to that of the DF membrane fraction of wild-type), a prominent band around $38 \mathrm{kD}$ and minor bands of lower molecular weight, recognized by the anti-Cx50 polyclonal antibody. The MF-NF pattern of wild-type lens (Figure 3A, lane 2), is characterized by a weaker band around $66 \mathrm{kD}$ and a major band around $38 \mathrm{kD}$. The MF-NF membrane fraction of Cx46 -/- lens (Figure 3A, lane 4), shows that the band around $66 \mathrm{kD}$ is absent, whereas several bands of lower molecular weight, ranging from $30-21 \mathrm{kD}$ are present corresponding to degraded forms of Cx50-polypeptides, recognized by the anti-Cx50 polyclonal antibody.

Figure 3B shows immunoblot patterns of DF and MF-NF membrane fractions of wild-type 
and Cx50 -/- lenses, using anti-Cx46J peptide antibody. The protein patterns recognized by this antibody in DF membrane fraction of wild-type lens (Figure 3B, lane 1) is characterized by the presence of a broad band around $55 \mathrm{kD}$ and several bands of lower molecular weight. In DF of Cx50 -/- lens, (Figure 3B, lane 3) the broad band around $55 \mathrm{kD}$ is also present., but the lower molecular weight bands are more prominent than in the wild-type DF membrane fraction.

In wild-type lens, the protein pattern of MF-NF membrane fraction (Figure 3B, lane 2) shows a weaker band around $55 \mathrm{kD}$ in comparison to its DF membrane fraction, and a major band with a molecular weight of $38 \mathrm{kD}$. Comparison between wild-type MF-NF membrane fractions and those of the Cx50 -/- lens shows that the $55 \mathrm{kD}$ band detected in Cx50 -/- lens (Figure 3B, lane 4), is weaker. Conversely, a major band around $38 \mathrm{kD}$ and several bands of lower molecular weight characterize this fraction.

Figure 3C depicts immunoblotting experiments of DF and MF-NF membrane fractions of Cx46 -/- and Cx50 -/- lenses, using the anti-MP26 antibody which recognizes the native and degraded forms of this polypeptide. DF membrane fraction of Cx46 -/- lens (Figure 3C, lane 1) and DF membrane fraction of Cx50 -/- lens (Figure 3C, lane 3) show almost the same pattern characterized by a heavily stained band around $26 \mathrm{kD}$. The MF-NF membrane fractions of $\mathrm{Cx} 46$-/- and Cx50 -/-lenses (Figure 3C, lanes 2 and 4), respectively show a prominent degradation of MP26 in the Cx46 -/- MF-NF fraction (lane 2) as compared to the weaker band in the MF-NF of Cx50 -/- lens (lane 4).

Figure 1D, shows the immunoblot patterns of DF (Figure 3D, lane 1) and MF-NF (Figure 3D, lane 2) membrane fractions of wild-type lens using the same anti-MP26 antibody. In DF (lane 1) a prominent band around $26 \mathrm{kD}$ is present. In MF-NF membrane fraction (lane 2) the pattern is characterized by the presence of a lower molecular weight band (around $22 \mathrm{kD}$ ) corresponding to a proteolytic fragment of MP26.

\section{Morphometry}

Fibers within $150 \mu \mathrm{m}$-width superficial layers

The equatorial diameters of the lens were measured and the half axes of the ellipsoid deduced from the homologous values described elsewhere (Kuszak and Costello, 2002 ; Kuszak et al., 2004). The Cx46-/- lens diameter is equivalent to that of the wild-type. Conversely, in 3 weeks-old Cx50 -/- mice, the lens diameter is reduced about $9 \%$. In view of the progressive fiber lengthening during development, only their putative maximal length was modeled. These fibers link the two opposites septa located at the lens poles. Their lengths range between 2.52-2.34 mm in wild-type and Cx46 -/-, and between 2.30-2.15 mm in Cx50 -/- lens (Table 1).

Fiber cell cross section:

Using anti-MP26 antibodies and/or rhodamine-labeled wheat-germ agglutinin (WGA), we delineated the honeycomb arrangement of DF cell membranes and measured the differences in size of the 3 mouse types (Figures 4A-4C). Measurements were done near the lens equatorial zone. The areas of cross sections were calculated either taking into account their hexagonal approximation or measured directly (Table 2A). The calculated values are $40.47 \pm$ $9.63 \mu \mathrm{m}^{2}$ for the wild-type, $30.19 \pm 9.90 \mu \mathrm{m}^{2}$ for $\mathrm{Cx} 46-/-$ and $106.83 \pm 12.96 \mu \mathrm{m}^{2}$ for $\mathrm{Cx} 50-/-$ mouse lens. These areas are of the same order of magnitude as the direct measurements giving support to the hexagonal approximation proposed in the adopted model (Table 2A).

These determinations show that in the superficial lens layers $(150 \mu \mathrm{m}$-width $)$, the fibers of Cx50 -/- lens have the largest cross section areas, whereas those of the Cx46 -/- lens have the smallest.

Three-dimensional cell shape factor $(R)$ within the $150 \mu m$-width superficial layers: The values for wild-type, Cx46 -/-and Cx50 -/- fiber cells are $312.78(\approx 313), 385.92(\approx 386)$ 
and $123.18(\approx 123)$, respectively. Thus, classifying the fibers according to their maximum stretching (i.e. elongation), the order is: Cx46 -/-, wild-type, Cx50 -/-, the Cx46 -/- fiber cells being the more elongated.

Fiber cell number:

The total number of fiber cells on the superficial layers (150 $\mu \mathrm{m}$-width), ranges between 21 $25 \times 10^{3}$ cells (mean $23 \times 10^{3}$ ) in the wild-type (taken as $100 \%$ ). In Cx46 -/- lens this number range is $26-38 \times 10^{3}$ cells (mean $32 \times 10^{3}$ ), representing an increase of $39 \%$. Conversely, in Cx50 -/- lens the total number of fibers is reduced to about 7,5-8,6 x $10^{3}$ cells (mean 8,05 x $10^{3}$ ), a decrease of $65 \%$ (Table $\mathbf{2 B}$ ).

Cell wall partition:

We calculated the portion of the fiber cell perimeter corresponding to radial and tangential walls for each fiber of the superficial layers (150 $\mu \mathrm{m}$-width) and the sum of walls of all fibers composing these superficial layers. In Cx46 -/- lens, the perimeter of the tangential and radial membranes of each fiber decreases by 7 and $17 \%$, respectively compared to the wild-type (Table 3). In the Cx50 -/- lens, the tangential membrane perimeter decreases by $17 \%$, whereas that of the radial membrane increases by $139 \%$ (Table 3). These data suggest that the main factor affected by the targeted disruption of $\mathrm{Cx} 46$ and of Cx50 is the radial dimension of each fiber cell.

Correlatively, the total length of the radial perimeters corresponds to an increase of $20 \%$ in Cx46 -/- lens and a decrease of $13 \%$ in Cx50 -/- lens (Table 3). The total length of the tangential perimeters increases of about $29 \%$ in Cx46 -/- lens and decreases of $70 \%$ in Cx50 -/- lens.

There are 41 cell layers for the wild-type, 49 cell layers for $\mathrm{Cx} 46$-/ and only 18 cell layers for Cx50 -/- lens. These values are correlated to the different number of fiber layers forming the (150 $\mu \mathrm{m}$-width) superficial cell layers.

Morphological gradient along the lens radius:

The morphological parameters of the fiber cross-sections along the lens radius within DF, MF and NF strata are shown in Table 4. The values of the minor and major axes measured for the DF regions are compatible with the values of Table 2. We estimated the total number of fiber cells considering 3 concentric regions : external, medial and central. The morphological gradient of the fiber cells in the wild-type and Cx50 -/-mice lens was calculated (Table 4). Conversely, for Cx46 -/- lens these calculations could not be carried out due to the presence of nuclear cataract. The central volume of the lens in wild-type and in Cx50 -/- contains fibers of homologous transversal sections. This region was considered as the image of the lens at birth (PO: post- natal day zero). (Table 5). Calculations of the probable diameters for wild-type and Cx50 -/- lens were deduced from growth curves of mouse lens (Bassnett, 1995 ; Bassnett and Mataic, 1997 ; Bassnett, 2002 ; Bassnett and Winzenburger, 2003 ; White et al., 1998). Their diameter equals $670 \mu \mathrm{m}$ and contains approximately $16 \times 10^{3}$ fiber cells.

The fiber cells of Cx50 -/- and wild-type lens from the medial region are morphological intermediates between cells of the external and central region. The number of fibers added during post-natal growth in wild-type and Cx50 -/- lens is 80,000 and 35,000 cells, respectively, corresponding to a decrease of more than $56 \%$ in the Cx50 -/- lens (Table 5). Taking into consideration the structural homology between the nuclear fiber region of these two lens types, the estimated total number of fiber cells is about 96,000 in the wild-type and about 51,000 in Cx50 -/- lens, corresponding to a decrease of about $47 \%$.

The process of fiber cell differentiation in wild-ype, $\mathrm{Cx46}$

The size and shape of the whole lens in Cx46 -/- mice do not diverge from those of the wild-type. Conversely, Cx50 -/- mouse lenses have a smaller size and are more round-shaped. In Figure 5A, the antero-posterior axis of Cx46 -/- corresponds to $850 \mu \mathrm{m}$, whereas the same axis for Cx50 -/- lens corresponds to $660 \mu \mathrm{m}$ (Figure 5B). Furthermore, the bow region 
(depicted by DAPI nuclear staining) is extended $120 \mu \mathrm{m}$ above and $170 \mu \mathrm{m}$ below the equatorial axis in Cx46 -/- lens (Figure 5A). In Cx50 -/- lens, the bow nuclear array occupied a larger region, from $180 \mu \mathrm{m}$ above to $240 \mu \mathrm{m}$ below the equatorial axis (Figure B).

In Cx46 -/- and wild-type lenses several steps of chromatin degradation have been found (Basnnett and Mataic,1997; DeMaria and Arruti, 2004). In Cx46 -/- lens, the nuclear degradation becomes apparent in the superficial fiber cells of the bow zone. Conversely, in Cx50 -/- lens, the denucleation process occurs only in the most inner fiber cells.

We restricted our immunocytochemical analyses of cryosections to two markers of the fiber cell differentiation: lamin $\mathrm{A} / \mathrm{C}$ and $\mathrm{KDEL}$, the latter being an endoplasmic reticulum (ER)specific marker. In wild-type, at the most superficial bow layer, the nuclei are round-shaped without obvious chromatin condensation. At this stage, the nuclei were encircled by intensely fluorescent ER membrane profiles (Figure 6A). In the bow region of $\mathrm{Cx} 46$-/- lens, nuclei are present in a limited amount of rows. Even in the outermost fiber cell layers cytoplasmic organelles were dismantled, particularly the ER membrane compartments (Figure 6B). In Cx50 -/- lens, larger fiber cells of the superficial layers are characterized by the permanence of cytoplasmic organelles, particularly KDEL-immunolabeled ER membrane profiles and the nuclear envelope (Figure 6C). With the aid of a specific antibody we monitored the lamin $\mathrm{A} / \mathrm{C}$ degradation, as a marker of the proliferative-quiescent status of the fiber cells (Pugh et al., 1997). In the wild-type, the denucleation process is characterized by a progressive degradation of lamin A/C, (Figure 6D). The fluorescent signal, which is rather intense in the outermost bow region, decreases progressively in deeper regions where only few small fragments of lamin A/C, are detected. In Cx46 -/- lens, the lamin A/C perinuclear profiles are characterized by a weaker fluorescence intensity compared to the wild-type lens (Figures 6E and 6F). Remarkably, lamin $\mathrm{A} / \mathrm{C}$ perinuclear profiles are almost completely disrupted in deeper layers. In this region, a number of small clumps are immunolabeled with anti-lamin A/C antibody (Figure 6F). In Cx50 -/- lens, the lamin A/C perinuclear fluorescent signal is particularly strong. Thick fluorescent profiles encircled the nuclei even at deep bow regions (Figure 6G).

The immunocytochemical analysis of cryosections from wild-type and Cx46 -/- lenses, using anti-MP26 antibody shows that this antibody outlines exclusively the fiber cells plasma membrane profiles (Figures 4A-4B). In Cx50 -/- lens, the larger fiber profiles and the presence of intracellular membranes are shown by using rhodamine-labeled WGA (Figure 4C). MP26-labeled Cx50 -/- lens cryosection shows that MP26 outlines the fiber profiles and is condensated along the plasma membrane in fluorescent clumps. Some MP26-positive material is also found in the cell cytoplasm (Figure 4D).

We compared the ultrastructure of the lens superficial cortical fiber cells (DF) in the three types of mice (Figures 4E - 4G). In wild-type (Figure 4E) and in Cx46 -/- DF (Figure 4F), cytoplasmic organelles are deleted. Conversely, ER profiles, Golgi stacked cisterns and small mitochondria characterized Cx50 -/- DF; vesicles and membrane profiles invaginations are present in close proximity to the plasma membrane (Figure 4G).

Freeze-fracture (FF) and Fracture-labeling (FL) of wild-type, Cx46 -/- and Cx50 -/fiber cell membranes

In wild-type lens, double FL using antibodies directed against Cx46 and Cx50 shows that both connexins are co-assembled and form junctional plaques and rows of junctional intramembranous particles (IMP, $9 \mathrm{~nm}$ diameter), on DF (Figure 7A). The junctional domains are encircled by immunogold-labeled MP26 (Figure 7B).

FL of MF-NF shows that membrane fracture faces are characterized by areas where IMP on $\mathrm{PF}$ and the corresponding pits on EF form geometrically packed arrays with a center-to-center spacing of 7-8 $\mathrm{nm}$ (lattice organization) (Figure 7C). The lattice organization comprises 
Cx46, Cx50 and MP26 (Figure 7C, inset).

In Cx46 -/- lens, the most impressive aspect of DF membranes is the extension of the junctional domains characterized by randomly distributed $9 \mathrm{~nm}$ IMP (Figures 8A and 8B). MP26 immunogold-labeling forms a rather distinct borderline around the junctional plaques (Figures 8A and 8B) MP26 appears in close topographic association with rows and clusters of IMP ( 9 nm diameter) (Figure 8B). Double immunogold labeling of the junctional plaque using anti-Cx50 and anti-MP26 antibodies shows that MP26 not only encircled but expands inside the junctional domain, immunogold-labeled with anti-Cx50 antibody (Figure 9A). In this type of DF gap junctions, the IMP are either randomly distributed or hexagonally-packed with a center-to-center distance of 7-8 $\mathrm{nm}$ (Figure 9A).

After filipin treatment, DF membrane fracture faces are characterized by the presence of 20$30 \mathrm{~nm}$ protuberances (PF) and grooves (EF) corresponding to filipin-induced lesions (FIL) of the bilayer. FIL are randomly distributed in non-junctional membrane fracture faces and are segregated from the junctional domains void of FIL (Figure 9B). The same is the case in wild-type DF junctional plaques (not shown).

FF and FL of Cx46 -/- MF show the presence of very extensive areas of geometricallypacked arrays of 7-8 nm repeating subunits in PF and geometrically-assembled pits on EF (Figures 10A and 10B). FL shows that the geometrical lattice is intensely immunogoldlabeled by antibodies raised against Cx50 and MP26 (Figure 10B). In thin sections of embedded MF-NF compartment, long, thin pentalaminar profiles (10-11 nm thick) are observed (Figure 10C) likely corresponding to the membrane segments occupied by the geometrical lattice visualized by FF.

After filipin treatment of Cx46 -/- MF, FIL are completely segregated from the lattice structures and filled the space between the geometrically-packed arrays of particles and pits (Figure 10D).

In Cx50 -/- DF, FF splits the plasma membrane in an irregular stepwise fashion and exposes fragmented areas of EF and PF (Figure 11A). FL shows that MP26 is randomly distributed without obvious localization encercling the small junctional domains immunogold-labeled by Cx46 antibody. In thin sections of Cx50 -/- DF embedded samples, segments of close aposition of two plasma membranes have an irregular pentalaminar profile with variable thickness (Figure 11B). Freeze-fracture of filipin-treated DF revealed that FIL are irregularly scattered on the fracture faces of the junctional plaques (Figure 11C).

In Cx50 -/- MF, FL revealed the presence of areas where 7-8 nm particles on PF and pits on $\mathrm{EF}$, formed a lattice structure (Figure 12). The lattice organization is segregated from areas where loosely packed $9 \mathrm{~nm}$ junctional particles are assembled. This junctional domain is labeled with anti-Cx46 antibody (Figure 12). The lattice structure, characterized by a prevailing hexagonal arrangement is immunogold-labeled with anti-MP26 antibody (Figure 12, inset).

FF of Cx50 -/- filipin-treated MF-NF, shows that FIL are localized at the interspaces between the lattice structure, presumably where junctional domains have been visualized (Figure 13).

\section{DISCUSSION}

\section{Changes of the overall organization of $\mathrm{Cx} 46$-/- and $\mathrm{Cx50}$-/- lens fiber cells}

Patterns of lens cell organization in vivo correlate with distinct interactions with the ocular media. The anterior region of the lens is bathed with the aqueous, whereas the region below the equator interacts with the vitreous humor. Therefore, epithelial cell growth and fiber cell differentiation are determined by an antero-posterior gradient of growth factors, receptors and signal-regulated pathways (Hyatt and Beebe, 1993; Kawauchi et al., 1999; Lang, 1999; Lovicu and McAvoy, 2005; McAvoy et al., 1999; Menko, 2002). Lens cell division predominantly occurs in the epithelial region, just above the lens equator (germinative zone), 
and proceeds at a non-uniform rate. Particularly during the post-natal period the number of mitoses increases remarkably (Gerido et al., 2003; Mathias et al., 1997; Menko, 2002; Shen Lin et al., 1998). The progeny of cell division migrates close to the equator into the transitional zone where the epithelial cell withdraws from the cell cycle and initiates elongation and differentiation. These processes are accompanied by a considerable increase of lens mass and of the surface-to-volume ratio of the fiber cells (Bassnett and Winzenburger, 2003; Kuszak, 1995; Kuszak, et al.,2004; Mathias et al., 1997). The differentiation process involves a progressive disruption of fiber cell nuclei and other cytoplasmic organelles with exception of the cytoskeleton and polyribosomes embedded in the water-soluble crystallin matrix (Bassnett, 1995; Bassnett and Mataic, 1997; Bassnett, 2002; Bassnett and Winzenburger, 2003 Benedetti, et al., 1996, Bloemendal et al., 2004).

The lens comprises fiber cells of different ages in a precise sequence along the anteroposterior and the equatorial axes. Therefore, the morphometric analyses that we carried out could unravel the initiation and progression of the alterations in Cx46, and Cx50 knockout lenses. We demonstrated that Cx46-/- lens is characterized by a post-natal increased density of smaller, stretched, hexagonally-shaped fiber cells. Likely the abrupt degradation of fiber cell organelles, particularly disruption of ER membrane profiles and of the nuclear lamin A/C, reveal the enhanced fiber cell differentiation (Bassnett, 1995 ; Bassnett and Mataic, 1997 ; Bassnett, 2002 ; Bassnett and Winzenburger, 2003 , De Maria and Arruti, 2004; Pugh et al., 1997). It is tempting to assume that the accelerated process of growth and differentiation in Cx46 -/- lens is driven by the expression of the Cx50 gene. Indeed, in primary cultures of chick lens, Cx45.6, orthologue of the rodent Cx50, stimulated epithelial cell growth, fiber cell differentiation, MP26 and crystallin expression (Gu et al., 2003).

Previous investigations led to the conclusion that the post-natal lens mass deficit in Cx50 -/mice resulted from the reduction of post-natal cell divisions yielding fewer undamaged fiber cells (Sellito et al., 2004; White et al., 1998; White, 2002). The present study shows that the decreased proliferation of the epithelium is not the unique feature that characterized the defective lens organization in Cx50 -/- mice. In the germinative and transitional zones a reduced number of abnormally large fiber cells are found that have adopted round-shaped cross sections. Furthermore, permanence of cytoplasmic organelles, particularly ER compartments and lamin $\mathrm{A} / \mathrm{C}$ nuclear profiles, indicated that the targeted ablation of the Cx50 gene not only reduced the number of mitotic cells (Sellito et al., 2004), but operated upon the checkpoint of the epithelial cells to withdraw from the cell cycle and differentiate into fiber cells. Strikingly Cx 50 -/- lens has structural features comparable to transgenic mice expressing FGFR3, truncated FGF and misexpression of IGF-1 (Govindarajan and Overbeek, 2001; Robinson et al., 1995; Shirke et al., 2001; Stolen and Griep, 2000). The common characteristics are microphthalmia associated with decreased number of cell divisions, increased number of nuclei that do not disintegrate and expand preferentially below the equator, delay of fiber cell differentiation and the enlargement of nucleated round-shaped fiber cells. Those morphological resemblances may suggest that Cx50, in parallel to growth factors or receptors, acts upon the control of growth and differentiation of the epithelial cell lineage according to the lens antero-posterior regulatory pattern (Hyatt and Beebe, 1993; Lovicu and McAvoy, 2005).

\section{Topographic interactions between $\mathrm{Cx50,} \mathrm{Cx46}$ and MP26}

We further analyzed the ultrastructural and immunocytochemical alterations associated with the modifications of the overall organization of the fiber cells in the two knockout phenotypes revealed by the morphometric study.

In previous investigations using FL we demonstrated that during junctional assembly in wildtype lens DF, immunogold-labeled MP26 appeared topographically distributed around the junctional plaques, composed by both Cx46 and Cx50 (Benedetti et al., 2000; Dunia et al., 
1998). We assumed that MP26, acting as an adhesion protein, was instrumental during the junctional assembly. This assumption was further supported by emerging experimental evidence showing that connexin-binding proteins play a role in the guiding of connexins to the site of gap junction assembly between two cells, in the stabilization of the junctional plaque and likely, in signal transduction (Duffy et al., 2002---). Specifically it has been shown that in differentiating chick lens fiber cells, MP26 (Aquaporin 0) and connexins interact via a molecular link between the MP26 C-terminus and the cytoplasmic loops of connexin 45.6. The Cx56, orthologue of the mouse Cx46, was immunoprecipitated and pulled down only if this connexin isoform was co assembled with the 45.6 (Cx50) (Yu and Jiang, 2004; Yu et al., 2005). The structural consequence of the specific interaction between M26 and one or the other fiber cell connexins is revealed by the application of FL to the two knockout phenotypes. In Cx46 -/- DF, the large junctional domains comprising Cx50 connexons, have a topographic interaction with MP26 comparable to that of the wild-type DF cells. Conversely in Cx50 -/- DF, the small junctional plaques where Cx46 was recruited, have no obvious topographic interaction with MP26. Immunofluorescence, of lens cryosections with antiMP26 antibody in Cx50-deficient lens, has shown that MP26 is abnormally accumulated along the plasma membrane or formed membrane profiles in the fiber cell cytoplasm. Ultrastructural alterations of the gap junction pentalaminar profile organization were also detected by thin section analysis. Hence it is tempting to assume that in Cx50 -/- lens, where MP26 expression is comparable to normal lens (White, 2002), the missing link between MP26 and Cx46, affects junctional assembly and in turn the maintenance of the structural organization of the fiber cells added during the post-natal period. This view is also reinforced by the results of other investigations on mice MP26-deficient or expressing chimerical AQPO-LTR (Al-Ghoul et al., 2003; Shiels et al., 2000). The alterations of the lens fiber cell organization described in these studies are comparable to the ultrastructural features that we observed in Cx50 -/- lens.

The topographic interactions between MP26 and connexins and their packing organization vary progressively in deeper regions of wild-type lens. There, connexins and MP26 undergo age-related cleavage of the cytoplasmic loops and C-termini (Jacobs et al., 2001; Jacobs et al., 2004). These biochemical changes are associated with the emergency of membrane domains displaying a geometrical assembly of repeating subunits (lattice organization). The lattice organization in wild-type lens fiber membranes was considered to be made exclusively by MP26 (Costello et al., 1992; Dunia et al., 1996). This view was corroborated by investigations showing that purified MP26 reconstituted in proteoliposomes, assembles in the lipid bilayer forming a lattice structure comparable to that visualized in aged lens fibers (Dunia et al., 1987). Other in vitro experiments demonstrated that purified MP26 forms bidimensional double-layered lattices of repeating tetragonal oligomers (Fotiadis et al., 2000; Gonen et al., 2004). The assembly of geometrically packed oligomers is a relevant feature of several aquaporin family members (Schenk et al., 2005). On the other hand, the ability of connexins to form geometrical lattices of repeating subunits has been also demonstrated by reconstitution experiments of purified connexins. Two-dimensional crystals of a recombinant 30-kDa C-terminal truncation mutant of connexin $43(\mathrm{Cx} 43)$ have been obtained (Unger et al., 1999). Detergent-solubilized Cx50 and its proteolytic fragment of $38 \mathrm{kDa}$, have been shown to assemble in vitro forming a lattice structure. Strikingly immunoblot analysis of the reconstituted lattice of Cx50 (38 kDa) also revealed the presence of MP26 (Kistler et al., 1993; , Kistler et al., 1994, Lampe et al., 1991).

The application of FL showed that in the wild-type MF-NF the lattice organization consists of MP26, Cx46 and Cx50. In Cx46 -/- MF-NF, Cx50 and MP26 form geometrically-packed arrays. Conversely, Cx46 expressed alone in Cx50 -/- lens behaves in a different fashion with MP26. We observed that in MF-NF of Cx50 -/- lens, Cx46 organized in clusters of randomly 
distributed $9 \mathrm{~nm}$ IMP, is segregated from the lattice organization formed by MP26 (7-8 nm IMP).

These results show that the packing organization of Cx46 and Cx50 in the lens membrane environment differes when they are co-assembled or expressed separately in the two knockout phenotypes. The electrophysiological analyses have already shown that Cx46 and Cx50 have distinct coupling and gating properties upon co-assembly compared to the functional parameters of one or the other connexin alone (Beahm and Hall, 2002 ; Ebihara et al., 1999; Hopperstad et al., 2000 ; Mathias et al., 1997 ; Mathias and Rae, 2004).

An interesting question concerns the functional involvement of the remodeling of the gap junction packing arrangement and of the emergency of a lattice organization deeper in the lens.

\section{Packing organization of the junctional domain in $\mathrm{Cx} 46$-/- and in $\mathrm{Cx50}$-/- lens}

Electrophysiological investigations have shown that in Cx46-/- DF communication compartments, the values of the coupling conductance were considerably reduced (60-70\%) (Baldo et al., 2001; Gong et al., 1998). Surprinsingly, the junctional domains in Cx46 -/- DF were remarkably extensive. The discrepancy between the low values of the junctional coupling and the presence of assembled junctional plaques can be explained taking into account that several comparative structural and electrophysiological experiments have shown that the values of junctional conductance could be disproportionably small in respect to the number and extension of junctional plaques (Kawauchi et al., 1999; Le and Musil, 2001; Mathias et al., 1997). The efficiency of the junctional coupling correlates more with the packing organization of the connexons, rather than the number and extension of the junctional plaques (Sosinsky, 1996). Indeed, we observed that the large junctional plaques in Cx46 -/DF were characterized by the presence of areas of geometrically-packed connexons. This type of organization has been correlated to the uncoupling state of the communicating pathway (Peracchia, 1977; Peracchia et al., 2000). This assumption is further supported by the demonstration that in the MF communication compartments where the junctional coupling was brought to zero (Baldo et al., 2001; Gong et al., 1998), the gap junctional domains were replaced by very extensive areas of geometrical arrays of particles forming a lattice structure. FL demonstrated that the geometrical arrays of particles comprise Cx50 and MP26. Immunoblot experiments of Cx46-/- DF and MF isolated membranes, showed that Cx50 and MP26 were proteolytically degraded. All these data suggest that in Cx46 -/- lens the impairment of cell-cell communication is the consequence of the accelerated proteolytic degradation of Cx50 and MP26 and the remodeling of the specialized membrane domains into a lattice organization unable to insure junctional coupling.

In Cx50 -/- DF and MF compartments, electrophysiological and tracer experiments have shown a minor reduction of the junctional and metabolic coupling (White et al., 1998). The permanence of junctional coupling likely correlates with junctional domains formed by $\mathrm{Cx} 46$ connexons that appear non-geometrically packed. In parallel, western blot analysis of DF and MF membrane fractions revealed a minor degree of proteolysis of Cx46 and MP26 compared to wild-type. Even at deeper MF-NF regions, Cx46 junctional plaques are present, being segregated from the lattice structure. We may anticipate that $\mathrm{Cx} 46$ homomeric, homotypic connexons insure the junctional coupling preventing severe lens opacification.

\section{Lipid and Connexin interactions}

Using filipin cytochemistry and freeze-fracture, we tried to determine whether the junctional remodeling observed in the two knockout phenotypes is associated with a distribution of $\mathrm{Cx} 46$ and $\mathrm{Cx} 50$ in distinct lipid membrane domains. 
The polyene antibiotic filipin is though to specifically bind to sterols in the membranes. This interaction becomes visible in the freeze-fracture faces of the membrane lipid bilayer as bumps and grooves of about $25 \mathrm{~nm}$-diameter. The filipin-induced lesions (FIL) are the putative markers for the presence of sterol-rich membrane domains (Severs, 1981). However there are several examples of membranes that comprise cholesterol-rich domains, where FIL are not apparent (Severs, 1981). That is the case of gap junctions which contain a higher cholesterol and sphingomyelin content than the total membrane fractions (Alcala et al., 1982; Borchman et al., 2004; Henderson et al., 1979; Van Marle and Vrensen, 2000). This discrepancy can be explained taking into account that FIL are not apparent in membrane domains where the molar concentration of cholesterol is higher than the local concentration of filipin. Furthermore, high concentration of sphingomyelin may also compete with filipincholesterol interactions and as a consequence prevent FIL (Behnke et al., 1984a; Behnke et al., 1984b).

When filipin cytochemistry is applied to wild-type lens it appears that FIL are excluded from the junctional domains and from the lattice organization of repeating subunits found in the lenticular nuclear membranes. In Cx46 -/- lens where Cx50 is recruited alone, FIL are also excluded from the junctional plaques (DF) and lattice domains (MF-NF). Conversely, in Cx50 -/- lens, where the junctional domains comprise $\mathrm{Cx} 46$ connexons, FIL are not segregated from the junctional plaques. The experiments of $\mathrm{Cx} 46$ and $\mathrm{Cx} 50$ expression in heterologous systems show that when these two isoforms are co-expressed they are both addressed to a Triton-insoluble membrane fraction. In contrast, when they are expressed separately, only Cx46, but not Cx50, is selectively recruited in the Triton-insoluble membrane fraction (Locke et al., 2005; Schubert et al., 2002). This experimental evidence gives support to our conclusion that the two connexin isoforms expressed separately are targeted to lipid domains characterized by a distinct type of filipin-lipid interaction.

\section{Concluding Remarks}

This study provides novel structural and immunocytochemical information showing that lens fiber $\mathrm{Cx} 46$ and $\mathrm{Cx} 50$ have the potential to interact with each other and in turn to acquire specific associations with protein partners and distinct lipid domains. The assembly and remodeling of the packing organization of the junctional domains during differentiation, aging and cataractogenesis, reflect a dynamic interplay between Cx46, Cx50 and MP26 in parallel to substantial post-translational events. The morphometric and immunocytochemical alterations unraveled in the two knockout phenotypes are likely the consequence of the targeted deletion of one or the other connexin, but also of the misfunction of the connexin isoform that is expressed alone. In Cx46 -/- lens the failure of Cx50 to provide appropriated coupling and gating functions generates a severe ionic unbalance that results in accelerated proteolysis and a packing organization of the membrane constituents unable to insure lens homeostasis. In Cx50 -/- lens the alterations of the overall fiber cell organization are due to the deletion of $\mathrm{Cx} 50$ but also of the incompetence of Cx46 to interact with MP26.

\section{ACKNOWLEDGEMENTS}

We wish to dedicate the present work to the memory of our beloved friend and mentor the late Norton Bernie Gilula, who inspired and promoted this study. Freeze-fracture observations were initiated by George Klier, who was an outstanding student of the eye lens architecture. We gratefully acknowledge the stimulating discussions and help of Dr. Malcolm Wood (Scripps Res. Institute, EM facilities) and Dr. J. Kuszak (Rush University Medical Center, Dpt. Ophthalmology, Chicago, IL, USA) for his interesting suggestions on the topological organization of lens fibers. We acknowledge the skilled assistence in CLSM and image 
processing of Mrs. A. Malfait-Jobart and Miss M. Barre (from the Image Processing Plateforme of IJM, Paris ,France). We are grateful to Dr. T. White (Dpt. Physiol. and Biophys., State University of New York, Stony Brook, NY, USA) for his gift of anti-Cx50 polyclonal antibody and Dr. B. Buendia (Dpt. Cell Biology, IJM, Paris, France) for her gift of anti-lamin $\mathrm{A} / \mathrm{C}$ antibody.

This work was supported by a Collaborative Research grant from NATO International Scientific Exchange Programs on Lens Plasma Membranes and Cataract and by the French National Research Council (CNRS). E.L. Benedetti and H. Bloemendal have been supported by the Alcon Research Institute Awards and X. Gong by RO1 EY13849 and EY12808 from the National Eye Institute, USA.

\section{REFERENCES}

-Alcala, J., Katar, M. and Maisel, H. 1982. Lipid composition of chick lens fiber gap junctions. Curr. Eye Res., 2, 569-578.

- Al-Ghoul, K. J.,. Kirk, T., Kuszak, A. J., Zoltoski, R. K., Shiels, A. and. Kuszak, J. R. 2003. Lens structure in MIP deficient mice. Anat. Record, 273, 714-730.

- Baldo, G.J., Gong, X., Martinez-Wittinghan, F. J., Kumar, N. M., Gilula, N. B. and Mathias, R. T. 2001. Gap junctional coupling in lenses from alpha(8) connexin knockout mice. J Gen Physiol. 118:447-456.

- Baruch A., Greenbaum, D., Levy, E. T., Nielsen, P. A., Gilula, N. B., Kumar, N. M. and Bogyo, M. 2001. Defining a link between gap junction communication, proteolysis, and cataract formation. J. Biol. Chem. 276, 28999-29006.

- Bassnett, S. 1995. The fate of the Golgi apparatus and the endoplasmic reticulum during lens fiber cell differentiation. Invest Ophthalmol Vis Sci. 36, 1793-1803.

- Bassnett, S. and Mataic, D. 1997. Chromatin degradation in differentiating fiber cells of the eye lens. J. Cell Biol., 137, 37-49.

- Bassnett, S. 2002.Lens organelle degradation. Exp. Eye Res., 74, 1-6.

-Bassnett, S. and Winzenburger, P. A. 2003. Morphometric analysis of fibre cell growth in the developing chicken lens. Exp. Eye Res., 76, 291-302.

- Beahm, D.L., and Hall, J. L. 2002. Hemichannel and junctional properties of connexin 50. Biophys J. 82, 2016-2031.

- Belaïd, A., and Belaïd, Y. 1992. Reconnaissance des formes. Paris, Intereditions, Paris.

- Benedetti, E.L., Dunia, I., Dufier, J. L., Seng, Y. K. and Bloemendal, H. 1996. Plasma membrane-cytoskeleton complex in normal and cataractous lens. In The cytoskeleton. Vol. 3. J. Heskett, editor. JAI Press. 451-518.

- Benedetti, E.L., Dunia, I., Recouvreur, M., Nicolas, P., Kumar, N. M. and Bloemendal H. 2000. Structural organization of gap junctions as revealed by freeze-fracture and SDS fracture-labeling. Eur J Cell Biol. 79, 575-82. 
- Behnke, O., Tranum-Jensen, J., van Deurs, B.1984a.Filipin as a cholesterol probe.I.Morphology of filipin-cholesterol interaction in lipid model systems. Eur. J. Cell Biol., 35, 189-199.

- Behnke, O., Tranum-Jensen, J., van Deurs, B. 1984b. Filipin as a cholesterol probe. II. Filipin-cholesterol interaction in red blood cell membranes. Eur. J. Cell Biol., 35, 200-215.

- Berthoud, V.M., Tadros, P.N.,Beyer, E. C. 2000. Connexin and gap junction degradation. Method. Cell Biol. 20,180-187.

- Bloemendal H, De Jong W, Jaenicke R, Lubsen NH, Slingsby C, Tardieu A. 2004. Ageing and vision: structure, stability and function of lens crystallins. Prog Biophys. Mol. Biol.,86, 407-485.

- Borchman, D., Yappert, M. C.,Afzal, M. 2004. Lens lipids and maximum lifespan. Exp. Eye Res., 79, 761-768.

- Buendia B, Courvalin J. 1997. Domain-specific disassembly and reassembly of nuclear membranes during mitosis. Exp Cell Res. 230, 133-144.

- Bruzzone, R.,White, T. W., Paul, D. L.1994. Expression of chimeric connexins reveals new properties of formation and gating behavior of gap junctions channels. J. Cell. Sci. 107, 955967.

- Costello, M.J., Oliver, T.N., Cobo, L.N., 1992. Cellular architecture in age-related human nuclear cataracts. Invest. Ophthalmol. Vis. Sci. 34, 2174-2185.

- Coster, M., Cherman, J.L. 1985. Precis d'analyse d'images. editions du CNRS, Paris.

- Deen, P. M. T., van Os, C. H. 1998. Epithelial Aquaporins. Curr. Opin. Cell Biol. 10 : 435442 .

- De Maria, A., C. Arruti. 2004. DNAse I and fragmented chromatin during nuclear degradation in adult bovine lens fibers. Mol. Vis., 10, 74-82.

- Duffy, H. S., Delmar,M.,Spray, D.S. 2002. Formation of gap junction nexus: binding partners for connexins. J. Physiol. 96, 243-249.

- Dunia, I., Manenti, S., Rousselet, A., Benedetti, E. L. 1987. Electron microscopic observations of reconstituted proteoliposomes with the purified major intrinsic membrane protein of eye lens fibers. J Cell Biol. 105,1679-1689.

- Dunia, I., Smit, J.J.M., van der Valk, M. A., Bloemendal, H., Borst, P., Benedetti, E.L. 1996. Human Multidrug Resistance 3-P-Glycoprotein Expression in Transgenic Mice Induces Lens Membrane Alterations Leading to Cataract.J; Cell Biol., 132, 701-716.

- Dunia, I. Recouvreur, M., Nicolas, P., Kumar, N., Bloemendal, H., Benedetti, E. L. 1998. Assembly of connexins and MP26 in lens fiber plasma membranes studied by SDS-fracture immunolabeling. J Cell Sci. 111, 2109-2120. 
- Dunia, I. Recouvreur, M., Nicolas, P., Kumar, N., Bloemendal,H., Benedetti, E. L. 2001. Sodium dodecyl sulfate-freeze-fracture immunolabeling of gap junctions. Methods Mol Biol. $154,33-55$.

- Ebihara, L., Xu, X., Oberti, C., Beyer, E. C., Berthoud, V. M. 1999. Co-expression of lens fiber connexins modifies hemi-gap-junctional channel behavior. Biophys J. 76, 198-206.

- Fotiadis, D., Hasler, L., Müller, D. J., Stahlberg, H., Kistler J., Engel, A. 2000. Surface tongue-and-groove contours of the lens plasma membranes facilitate cell-to-cell adherence. J. Mol. Biol. 300, 779-789.

- Fujimoto, K., Nagafuchi, A., Tsukita, S., Kuraoka, A., Ohokuma, A., Shibata, Y. 1997. Dynamics of connexins, E-cadherin and alpha-catenin on cell membranes during gap junction formation. J Cell Sci. 110, 311-322.

- Gao, J., Sun,X., Martinez-Wittinghan, F.G., Gong, X.,White, T. W., Mathias, R.T. 2004. Connexions between connexins, calcium and cataracts in the lens. J. Gen. Physiol. 124, 289300.

- Gerido, D. A., Sellitto, C., Li, L.,White, T.W. 2003. Genetic background influences cataractogenesis, but not lens growth deficiency, in Cx50-knockout mice. Invest. Ophthal. Vis. Sci., 44, 2669-2674.

- Gonen, T., Cheng, Y., Kistler, J., Walz, T. 2004. Aquaporin-0 membrane junctions form upon proteolytic cleavage. J Mol Biol. 342, 1337-1345.

- Govindarajan, V., Overbeek, P.A. 2001. Secreted FGFR3 but not FGFR1, inhibits lens fiber differentiation. Development, 128, 1617-1627.

- Gong, X., Baldo, G.J. Kumar, N.M., Gilula, N.B., Mathias, R.T. 1998. Gap junctional coupling in lenses lacking alpha3 connexin. Proc Natl Acad Sci USA 95, 15303-15308.

- Gong, X., Li, E., Klier,G., Huang, G.,Wu,Y., Lei, H., Kumar, N.M., Horwitz, J., Gilula, N.B. 1997. Disruption of alpha3 connexin gene leads to proteolysis and cataractogenesis in mice. Cell. 91, 833-843.

- Gu, S., Yu, S., Yin, Y., Jiang, Y.X. 2003. Stimulation of lens cell differentiation by gap junction protein connexin 45.6. Invest. Ophthalmol. Vis. Sci., 44, 2103-2111.

Henderson, D., Eibl, H.,Weber, K. 1979. Structure and biochemistry of mouse hepatic gap junctions. J. Mol. Biol. 132, 193-218.

- Hertzberg, E.L., Anderson, D.J., Friedlande, R.M., Gilula, N.B. 1982. Comparative analysis of the major polypeptides from liver gap junctions and lens fiber junctions. J Cell Biol. 92, 53-59.

- Hyatt, G. A., Beebe., D. 1993. Regulation of cell growth and polarity by an embryo-specific growth factor and by inhibitors of lens cell proliferation and differentiation. Development, $117,701-709$. 
- Hopperstad, M. G., Srinivas, M. Spray, D. C. 2000. Properties of gap junctions channels formed by Cx46 alone and in combination with Cx50. Biophis. J. 79, 1954-1966.

- Jähne, B. 1993. Digital image processing. Springer-Verlag, Berlin.

- Jacobs, M.D.M., Soeller, C., Cannel, M.B., Donaldson, J.P. 2001. Quantifying changes in gap junction structure as a function of lens fiber cell differentiation. Cell Comm. \& Adh., 8, 349-353.

- Jacobs, M.DM., Soeller, C., Sisley, A.M.G., Cannell, M.B., Donaldson, J. P. 2004. Gap junction processing and redistribution revealed by quantitative optical measurements of connexin 46 epitopes in the lens. Invest. Ophthalmol. Vis. Sci., 45, 191-199.

- Jiang, J.X., Goodenough, D. A. 1996. Heteromeric connexons in lens gap junction channels. Proc Natl Acad Sci U S A. 93, 1287-1291.

- Kawauchi S., Takahashi, S., Nakajima, O., Ogino, H., Morita, M., Nishizawa, M.,Yasuda, K., Yamamoto, M. 1999. Regulation of lens fiber cell differentiation by transcription factor cMaf. J Biol Chem. 27, 19254-19260.

- Kistler, J., Goldie, K., Donaldson, P., Engel, A. 1994. Reconstitution of native-type noncrystalline lens fiber gap junctions from isolated hemichannels. J. Cell Biol., 126, 10471058.

- Kistler, J., Bond, J., Donaldson, P., Engel, A. 1993. Two distinct levels of gap junction assembly in vitro. J. Struct. Biol., 110, 28-38.

- Kistler, J., Berriman, J., Evans,C.W., Gruijters, W.T., Christie, D., Corin, A., Bullivant, S. 1990. Molecular portrait of lens gap junction protein MP70. J Struct Biol. 103, 204-211.

- Kumar N.M., Gilula, N.B.. 1996. The gap junction communication channel. Cell. 84, 381388 .

- Kuszak, J., Costello, L. 2002. Embryology and anatomy of the lens. In Duane's Clinical ophthalmology. W.T. Tasman and E. Jaeger, editors. Lippincot, Williams and Wilkins, Philadelphia.

- Kuszak, J.R. 1995. The ultrastructure of epithelial and fiber cells in the crystalline lens. Int Rev Cytol. 163, 305-350.

- Kuszak, J. R., Zoltoski, R. K., Silvertson, C. 2004. Fibre cell organization in crystalline lenses. Exp. Eye Res., 78, 673-687.

- Lang, R. 1999. Which factors stimulate lens fiber cell differentiation in vivo ? Invest. Ophthalmol. Vis. Sci., 40, 3075-3078.

- Lampe, P. D., Kistler, J.,Hefti, A., Bond,J., Müller, S., Johnson, R.G., Engel, A.1991. In vitro assembly of gap junctions. J. Struct. Biol., 107, 281-290. 
- Le, A.C., Musil, L.S. 2001. A novel role for FGF and extracellular signal-regulated kinase in gap junction-mediated intercellular communication in the lens. J Cell Biol. 154, 197-216.

- Locke D., Liu, J., Harris, A. L. 2005. Lipid rafts prepared by different methods contain different connexin channels, but gap junctions are not lipid rafts. Biochemistry, 44, 1302713042.

- Lovicu, F. J., McAvoy, J.W. 2005. Growth factor regulation of lens development. Dev. Biol., 280, 1-14.

- Martinez-Wittinghan, F.J., Sellitto, C., Li,L., Gong, X., Brink, P.R., Mathias, R.T.,White, T.W. 2003. Dominant cataracts result from incongruous mixing of wild-type lens connexins. J Cell Biol. 161, 969-978.

- Mathias, R.T., Rae, J. L., Baldo, J.G.. 1997. Physiological properties of the normal lens. Physiol Rev. 77, 21-50.

- Mathias, R. and Rae, J. L. 2004. The lens: local transport and global transparency. Exp. Eye Res., 78, 689-698.

- McAvoy, J. W., Chamberlain, C.G., de Iongh, R.U., Hales,A.M., Lovicu, F.J.,1999. Lens development. Eye, 13, 425-437.

- Menko, A. S., 2002. Lens epithelial cell differentiation. Exp. Eye Res., 75, 485-490.

- Milks, L.C., Kumar, N.M., Houghten, R., nwin, N., Gilula, N.B., 1988.Topology of the 32kd liver gap junction protein determined by site-directed antibody localizations. EMBO J.10, 2967-2975.

- Nielsen, P.A., Baruch, A., Shestopalov,V.I., Giepmans, B.N., Dunia, I., Benedetti, E..L., Kumar, N.M., 2003. Lens connexins alpha3Cx46 and alpha8Cx50 interact with zonula occludens protein-1 (ZO-1). Mol Biol Cell. 14, 2470-2481.

- Orci, L., Montesano, R., Meda, P., Malaisse-Lagae, R., Brown, D., Perrelet, A., Vassalli, P. 1981. Heterogeneous distribution of filipin--cholesterol complexes across the cisternae of the Golgi apparatus. Proc. Natl. Acad. Sci., 78, 293-297.

- Palanivelu, D.V., Kozono, D.E., Engel, A., Suda, K, Lustig, A, Agre, P, Schirmer, T. 2006. Co-axial association of recombinant eye lens aquaporin-0 observed in loosely packed 3D crystals. J. Mol Biol. 355, 605-611.

- Peracchia, C., Wang, X.G., Peracchia. L.L. 2000. Chemical gating of gap junction channels. Methods. 20, 188-195.

- Peracchia C., 1977. Gap junctions: Structural changes after uncoupling procedures. J. Cell Biol., 72, 628-641.

- Pugh, G. E., Coates, P. J., Lane, E. B., Raymond, Y., Quinlan, R.A., 1997. Distinct nuclear assembly pathways for lamins A and $\mathrm{C}$ lead to their increase during quiescence in Swiss 3T3 cells.J. Cell Sci., 110, 2483-2493. 
- Robinson, M. L., Mac-Millan-Crow, L.A.,Thompson, J., Overbeek, P.A.. 1995. Expression of a truncated FGF receptor results in defective lens development in transgenic mice. Development, 121, 3959-3967.

- Rong, P., Wang, X., Niesman, I., Wu, Y., Benedetti, E.L., Dunia, I., Levy, E., Gong, X. 2002. Disruption of Gja8 (alpha8 connexin) in mice leads to microphthalmia associated with retardation of lens growth and lens fiber maturation. Development. 129:167-174.

- Schenk, A. D., Werten, P. J., Scheuring, S., de Groot, B. L., Muller, S. A., Stahlberg, H., Philippsen, A., Engel, A. 2005. The 4.5 A structure of human AQP2. J Mol Biol., 350,:278289.

- Schubert, AL, Schubert, W., Spray, D. C., Lisanti, M. P. 2002. Connexin family members target to lipid raft domains and interact with Caveolin-1. Biochemistry, 41, 5754-5764.

- Sellitto, C., Li , L.,White, T.W. 2004. Connexin 50 is essential for normal postnatal lens proliferation. Invest. Ophthalmol. Vis. Sci., 45, 3196-3202.

- Severs, N. J. 1981. Plasma membrane cholesterol in myocardial muscle and capillary rndothelial cells. Distribution of filipîn-induced deformations in freeze-fracture. Eur. J. Cell Biol. 25, 289-300.

- Shen Lin, J., Eckert, R., Kistler, J., Donaldson, P.,1998. Spatial differences in gap junction gating in the lens are a consequence of connexin cleavage. Eur. J. Cell Biol., 76, 246-250.

- Shiels, A., Mackay, D., Bassnett, S., Al-Ghoul, K. and J. Kuszak. 2000. Disruption of lens fiber cell architecture in mice expressing a chimeric AQP0-LTR protein. Faseb J. 14:22072212.

- Shirke, S., Faber, S. C., Hallem, E. Makarenkova,H.P.,Robinson,M.L., Overbeek, P.A., Lang, R. 2001. Misexpression of IGF-I in the mouse lens expands the transitional zone and perturbs lens polarization. Mech. Develop., 101, 167-174.

- Sosinsky, G.E. 1996. Molecular organization of gap junction membrane channels. J. Bioenerg Biomembr. 28, 297-309.

- Stolen, C. M., Griep, A.E. 2000. Disruption of lens fiber cell differentiation and survival at multiple stages by region-specific expression of truncated FGF receptors. Devel. Biol., 217, 205-220.

- VanMarle, J., Vrensen, G. F.J.M.. Cholesterol content of focal opacities and multilamellar bodies in the human lens: filipin cytochemistry and freeze-fracture. Ophthalmic Res., 32, 285291. (2000).

-Varadaraj, K, Kushmerick, C, Baldo, G. J., Bassnett, S., Shiels, A, Mathias, R.T. 1999.The role of MIP in lens fiber cell membrane transport. J Membr. Biol., 170, 191-203. 
- Unger, V. M., Kumar, N. M., Gilula, N. B., Yeager, M. 1999. Expression, two-dimensional crystallization, and electron cryo-crystallography of recombinant gap junction membrane channels. J Struct Biol., 128, 98-105.

- White, T.W., Bruzzone, R., Goodenough, D.A., Paul, D.L. 1992. Mouse Cx50, a functional member of the connexin family of gap junction proteins, is the lens fiber protein MP70. Mol Biol Cell. 3:711-720.

- White, T.W., Goodenough, D.A.,Paul, D.L. 1998. Targeted ablation of connexin50 in mice results in microphthalmia and zonular pulverulent cataracts. J Cell Biol. 143:815-825.

- White, T. W., Paul, D.L., Goodenough, D.A.,Bruzzone, R. 1995. Functional analysis of selective interactions among rodent connexins. Mol. Biol. Cell. 6, 459-470.

- White, T.W. 2002. Unique and redundant connexin contribution to lens development. Science. 295, 319-320.

- Yu, X. S. and Jiang, J.X. 2004. Interaction of major intrinsic protein (aquaporin-0) with fiber connexins in lens development. J. Cell Sci., 117, 871-880.

- Yu, X. S., Yin, X., Lafer, E. M. , Jiang, J.X. 2005. Developmental regulation of the direct interaction between the intracellular loop of $\mathrm{Cx} 45.6$ and the C-terminus of major intrinsic protein (AQUA-0). J. Biol. Chem. 280, 22081-22090. 


\section{Table 1}

\begin{tabular}{|c|c|c|}
\hline Fiber rank & Wild type - Cx46 -/- & Cx50 -/- \\
\hline 1 & 2.47 & 2.27 \\
\hline 2 & 2.49 & 2.28 \\
\hline 3 & 2.50 & 2.30 \\
\hline 4 & 2.52 & 2.30 \\
\hline 5 & 2.51 & 2.30 \\
\hline 6 & 2.50 & 2.30 \\
\hline 7 & 2.49 & 2.28 \\
\hline 8 & 2.46 & 2.26 \\
\hline 9 & 2.43 & 2.23 \\
\hline 10 & 2.38 & 2.19 \\
\hline 11 & 2.34 & 2.15 \\
\hline & 2.46 & 2.26 \\
\hline Mean range & $2.34-2.52$ & $2.15-2.30$ \\
\hline
\end{tabular}

Values of the fiber lengths (eleven sectors) corresponding to the superficial layers (150 $\mu \mathrm{m}$-width) of wild-type, Cx46 -/- and Cx50 -/- mouse lens. The values (in $\mathrm{mm}$ ) were deduced from the model illustrated in appendix, Figure 1. 
Table 2 Dimensions of fiber cross sections of the superficial layers (150 um-width) of wild-type, Cx $46-/-$ and Cx50 -/- mouse lens

\begin{tabular}{|c|c|c|}
\hline Fiber rank & Wild type - Cx46 -/- & Cx50 -/- \\
\hline 1 & 2.47 & 2.27 \\
\hline 2 & 2.49 & 2.28 \\
\hline 3 & 2.50 & 2.30 \\
\hline 4 & 2.52 & 2.30 \\
\hline 5 & 2.51 & 2.30 \\
\hline 6 & 2.50 & 2.30 \\
\hline 7 & 2.49 & 2.28 \\
\hline 8 & 2.46 & 2.26 \\
\hline 9 & 2.43 & 2.23 \\
\hline 10 & 2.38 & 2.19 \\
\hline 11 & 2.34 & 2.15 \\
\hline & 2.46 & 2.26 \\
\hline Mean range & $2.34-2.52$ & $2.15-2.30$ \\
\hline
\end{tabular}

A: The fiber areas were measured directly using image analysis software, or calculated taking into account the values of their major and minor axis. The standard deviation (SD) was calculated from the partial derivative of the corresponding equation. The obtained values are rather homologous (calculated or measured mean areas).

\begin{tabular}{|c|c|c|c|}
\hline Mouse type & $\mathrm{N}^{\circ}$ fibers & Mean values & $\%$ vs. wild type \\
\hline Wild & $21,000-25,000$ & 23,000 & - \\
\hline Cx46 -/- & $26,000-38,000$ & 32,000 & $+39 \%$ \\
\hline Cx50 -/- & $7,500-8,600$ & 8,050 & $-65 \%$ \\
\hline
\end{tabular}

B: Ranges of the number of fibers of superficial layers (150 $\mu \mathrm{m}$ width), from wild-type,

Cx46 -/- and Cx50 -/- mouse lens. Calculations were done taking into account the major and minor axis ranges and the SD of the fibers shown in A. 


\section{Table 3}

Ranges of tangential and radial fiber cell walls from the superficial layers (150 $\mu \mathrm{m}$-width) of wild-type, Cx46 -/and Cx50 -/- mouse lens. Tangential cell wall values decreased as compared to wild-type in Cx46 -/- and Cx50 /- mouse lens. On the contrary, radial cell wall values of Cx50 -/- mouse lens were increased (139\%). Taking into account the total number of cells in the superficial layers $(150 \mu \mathrm{m}$-width), the total values of tangential and radial fiber cell walls show a respective increase of $29 \%$ and $20 \%$ in Cx46 -/- and a decrease of almost $70 \%$ and $13 \%$ in Cx50 -/- mice lens.

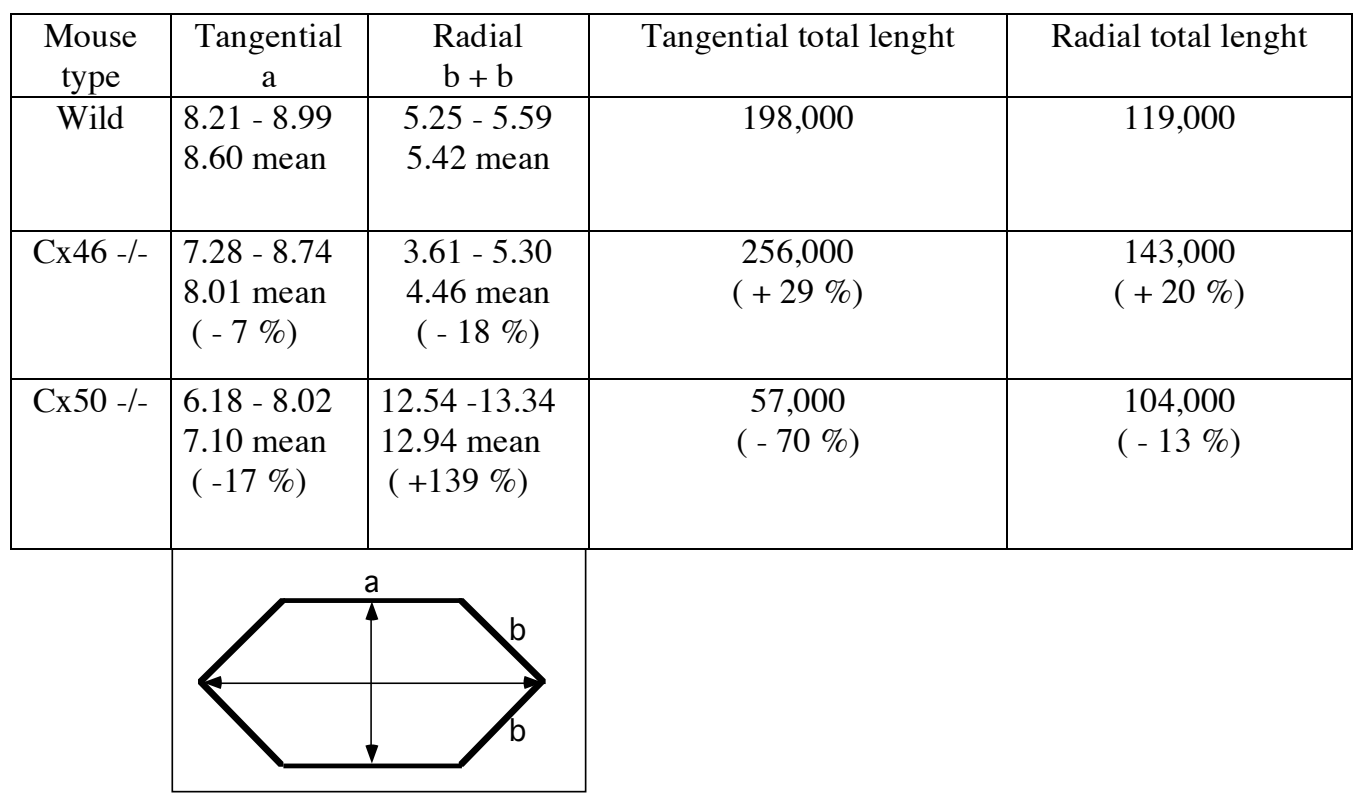




\section{Table 4}

Morphological gradient along the lens radius in wild-type and Cx50 -/- mouse lens. The values of the measured major and minor axis of differentiating fibers (DF) are compatible with the homologous values presented in Table 2. From the eccentricity values we can deduce that the transverse cross sections of mature fibers (MF) in wild-type lens are more flat in comparison to the other layers but Cx50 -/- nuclear lens fibers (NF) are the flattest.

\begin{tabular}{|c|c|c|c|c|c|c|c|}
\hline Mouse type & $\begin{array}{c}\text { Area } \\
\left(\text { pixels }^{2}\right)\end{array}$ & $\begin{array}{c}\text { Area } \\
\left(\mu \mathrm{m}^{2}\right)\end{array}$ & Eccentricity & $\begin{array}{c}\text { Minor axis } \\
(\text { pixels })\end{array}$ & $\begin{array}{c}\text { Minor axis } \\
(\mu \mathrm{m})\end{array}$ & $\begin{array}{c}\text { Major axis } \\
(\text { pixels })\end{array}$ & $\begin{array}{c}\text { Major axis } \\
(\mu \mathrm{m})\end{array}$ \\
\hline Wild DF & $2141.56 \pm 65.23$ & $37.84-40.22$ & $0.67 \pm 0.019$ & $28.24 \pm 1.04$ & $3.67-3.95$ & $93.70 \pm 3.00$ & $12.24-13.05$ \\
\hline Wild MF & $1950.32 \pm 42.61$ & $34.77-36.32$ & $0.76 \pm 0.014$ & $24.68 \pm 0.99$ & $3.20-3.46$ & $94.85 \pm 2.59$ & $12.45-13.15$ \\
\hline Wild NF & $1473.96 \pm 51.98$ & $25.92-27.81$ & $0.53 \pm 0.028$ & $26.11 \pm 0.72$ & $3.43-3.62$ & $70.70 \pm 2.67$ & $9.18-9.90$ \\
\hline Cx50 -/- DF & $6048.95 \pm 292.0$ & $104.92-115.56$ & $0.19 \pm 0.022$ & $63.39 \pm 1.41$ & $8.36-8.74$ & $116.82 \pm 2.03$ & $15.49-16.03$ \\
\hline Cx50 -/- MF & $3881.92 \pm 413.78$ & $63.21-78.29$ & $0.21 \pm 0.043$ & $52.27 \pm 1.65$ & $6.83-7.27$ & $89.87 \pm 3.03$ & $11.72-12.53$ \\
\hline Cx50 -/- NF & $1363.00 \pm 86.54$ & $24.39-25.29$ & $0.48 \pm 0.036$ & $26.23 \pm 0.94$ & $3.41-3.67$ & $64.96 \pm 1.91$ & $8.51-9.02$ \\
\hline
\end{tabular}




\section{TABLE 5}

Comparison between the estimated total number of fiber cells in wild-type and Cx50 -/- mouse lens in 3 concentric zones of the lens from the superficial layers, to the bulk of the lens mass and the central volume. PO represents post-natal day zero that corresponds to the same number of cells for Cx50 -/- and wild-type lens. The ranged values are 23,000 and 8,000 for the superficial layers, 57,000 and 27,000 for the median layer of wildtype and Cx50 -/- mice lens, respectively. The total post-natal cell addition corresponds to 80,000 fiber cells in the wild-type versus 35,000 for Cx50 -/- mouse lens. The systematic calculation error is about $10 \%$. This calculation could not be carried out in the Cx46-/- lens, because of the presence of nuclear cataract.

\begin{tabular}{|c|c|c|}
\hline Mouse type & Wild type & Cx50 -/- \\
\hline Total cell number & 96,000 & 51,000 \\
\hline Post natal cell addition & 80,000 & 35,000 \\
\hline
\end{tabular}

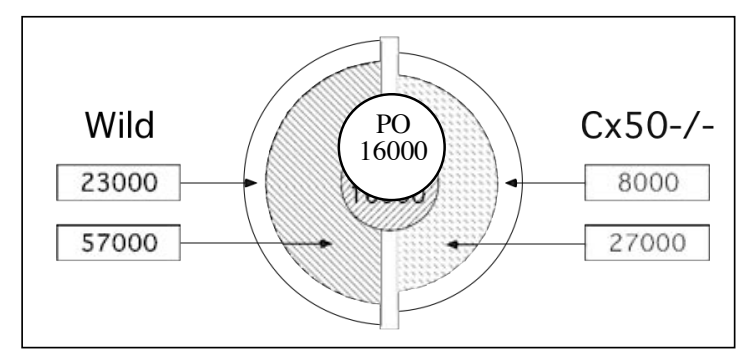

\section{$\underline{\text { Table } 5}$}

Comparaison between the estimated total number of fiber cells in wild type and Cx50 -/- mice

lens. 

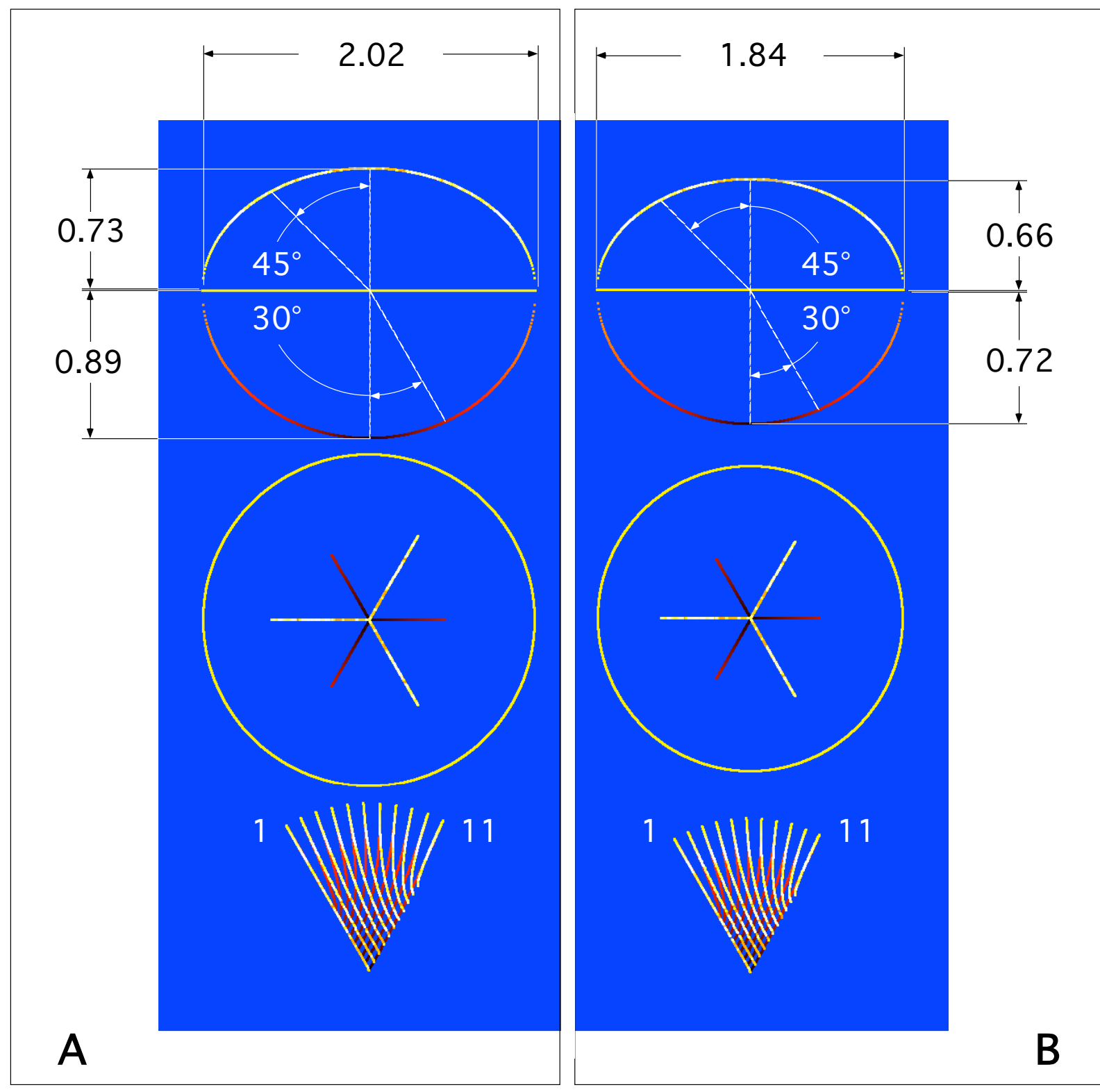

\section{Figure 1}

Diagram representing sagital, frontal cross-sections of the lens (upper and middle pannels respectively) and eleven surface sectors used to calculate morphological characteristics and lengths of superficial fiber cells (lower pannels). White lines correspond to anterior pole and equatorial region, red lines to posterior pole including suture lines.

A: wild-type dimensions. B: Cx50\% dimensions. 


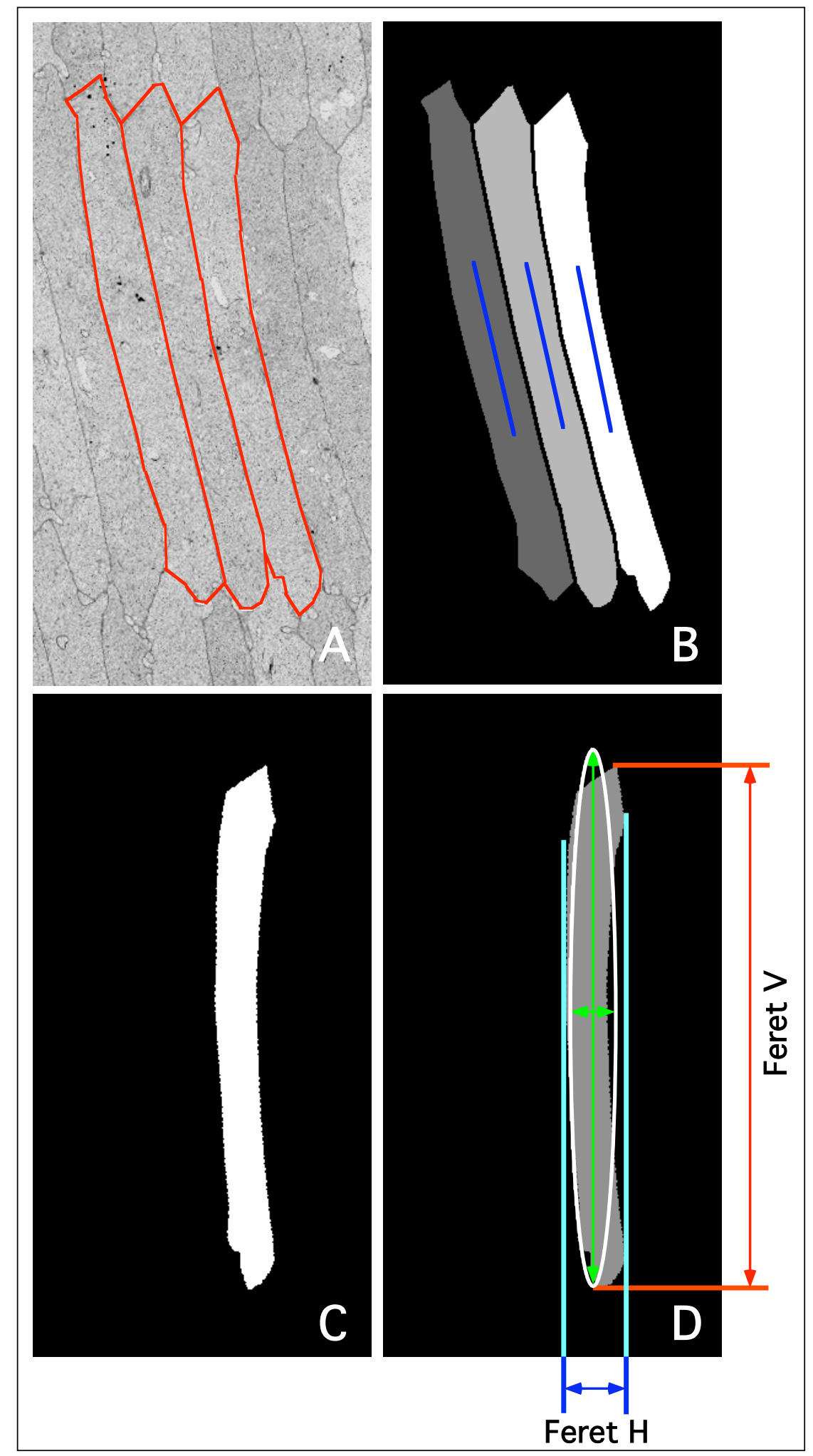

\section{Figure 2}

A: Wild-type fiber cross-sections, the outlined fibers represent the mask orientation in the image plane; B: Calculation of cross-section binary masks; C: Mask rotation as function of its orientation in the image plane; D: Representation of Feret diameter measurements, V: vertical; H: horizontal, in red and blue color lines, respectively. In green, axis of the mask equivalent ellipsoid. Major and minor axis of cross sections equal vertical Feret diameter and minor axis of the equivalent ellipsoid, respectively. 
A
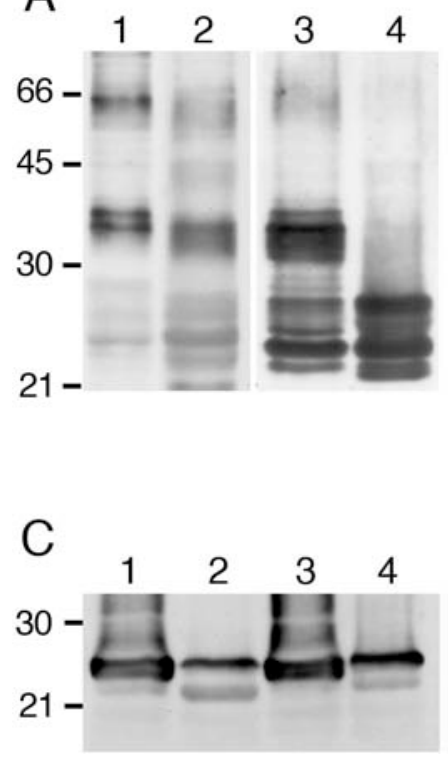

B

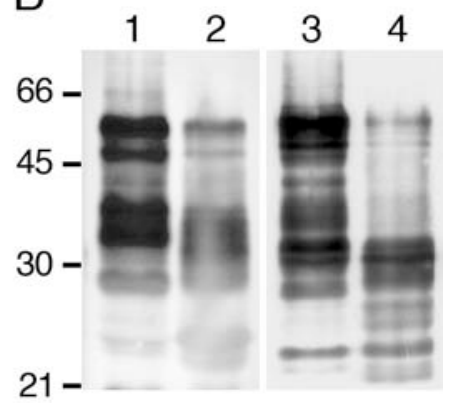

D

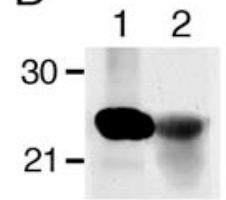

\section{Figure 3}

Immunoblot analysis of urea-insoluble DF and MF-NF membrane fractions of wild-type, Cx46 -/- and Cx50 -/lenses. Equal volume of the membrane fractions were analyzed by SDS-PAGE.

A : Protein blots of DF membrane fractions of wild-type (lane 1) and Cx46 -/- lenses (lane 3) and MF-NF membrane fractions of wild-type (lane 2) and $\mathrm{Cx} 46 \%$ lenses (lane 4) revealed with anti-Cx50 antibody. B : Protein blots of DF membrane fractions of wild-type (lane 1) and Cx50 -/- lenses (lane 3) and MF-NF membrane fractions of wild-type (lane 2) and Cx50 -/- lenses (lane 4) revealed with anti-Cx46J antibody. C : Comparison of the protein blots of DF (lane 1) and MF-NF (lane 2) membrane fractions from Cx46 -/- lens and the DF(lane 3) and MF-NF (lane 4) membrane fractions from Cx50 -/- lens revealed with anti-MP26 antibody.

D : Protein blots of DF (lane 1) and MF-NF (lane 2) membrane fractions from wild-type lens revealed with antiMP26 antibody. 

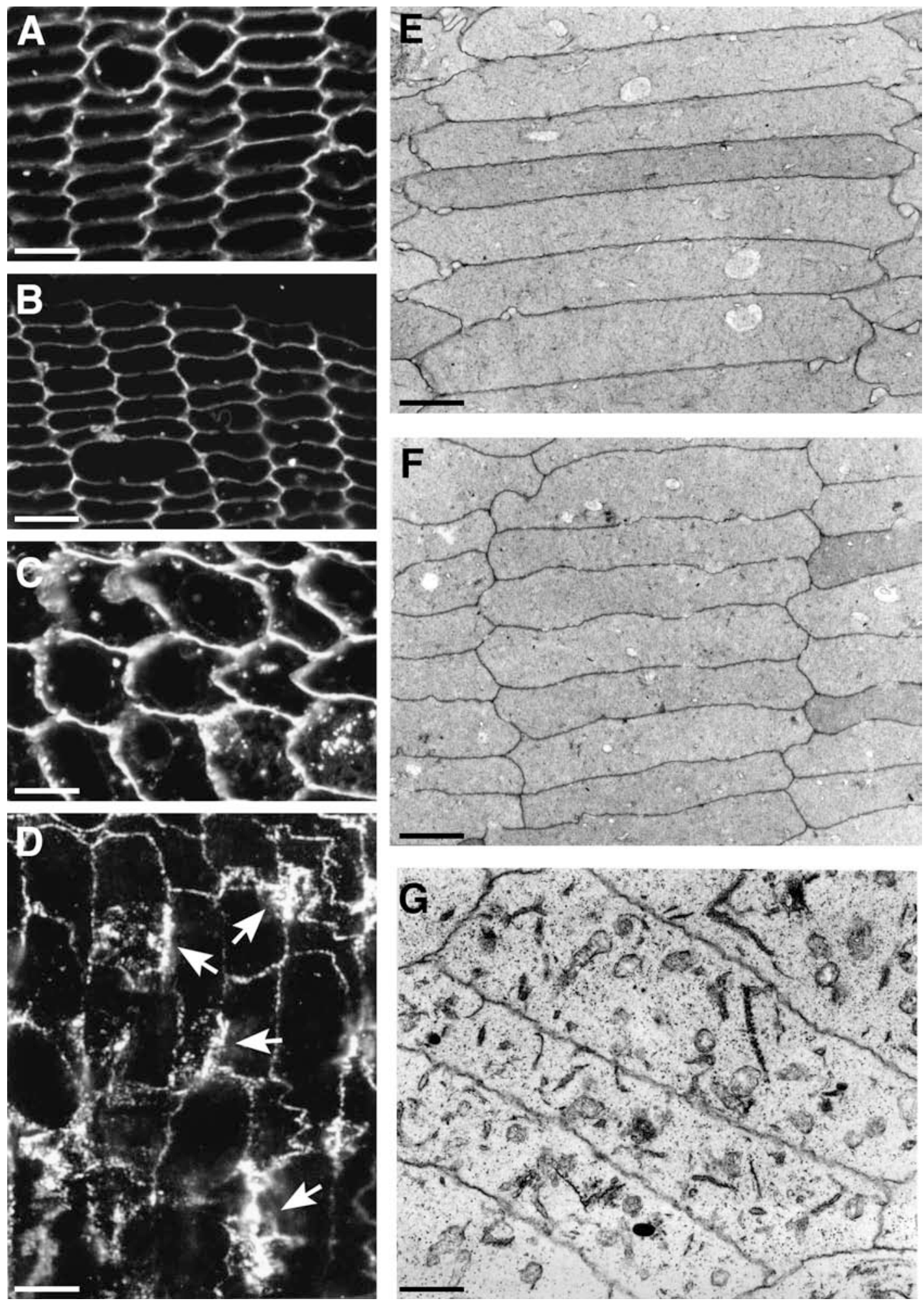

\section{Figure 4}

A - D : CLSM of transverse lens cryo-sections of superficial DF.

In A : wild-type and in B: Cx46 -/- lenses, both immunostained with anti-MP26.

In $\mathbf{C}$ and $\mathbf{D}: \mathbf{C x} 50$-/- DF cross-sections stained with rhodamine-labeled WGA and with anti-MP26 antibody, respectively. In $\mathbf{D}$, arrows point to accumulation of MP26 along the plasma membrane profiles.

Bars $=10 \mu \mathrm{m}$

$\mathbf{E}$ - G :Electron microscopic observations on thin sections of DF outer cortical region.

$\mathbf{E}:$ Wild-type, $\mathbf{F}: \mathrm{Cx} 46-/-$ and $\mathbf{G}:$ Cx50 -/- lenses.

Bars $=4 \mu \mathrm{m}$ 


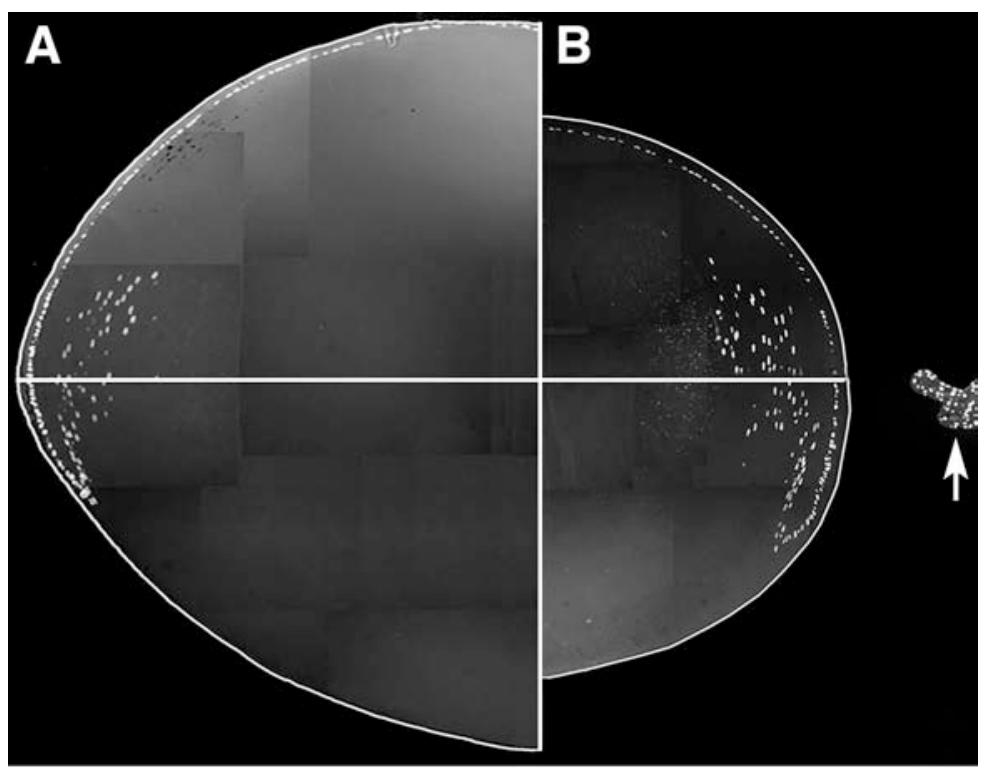

\section{Figure 5}

Cross sections of Cx46 -/- (A) and Cx50 -/- lenses (B).

The lens equator has been aligned to the ciliary body (arrow). Note that the Cx46 -/- lens bow zone (in $\mathbf{A}$ ) is characterized by a few arrays of nuclei, equally spread above and below the lens equator. In the smaller Cx 50 -/lens (in $\mathbf{B}$ ) the bow zone is largely expanded below the equator.
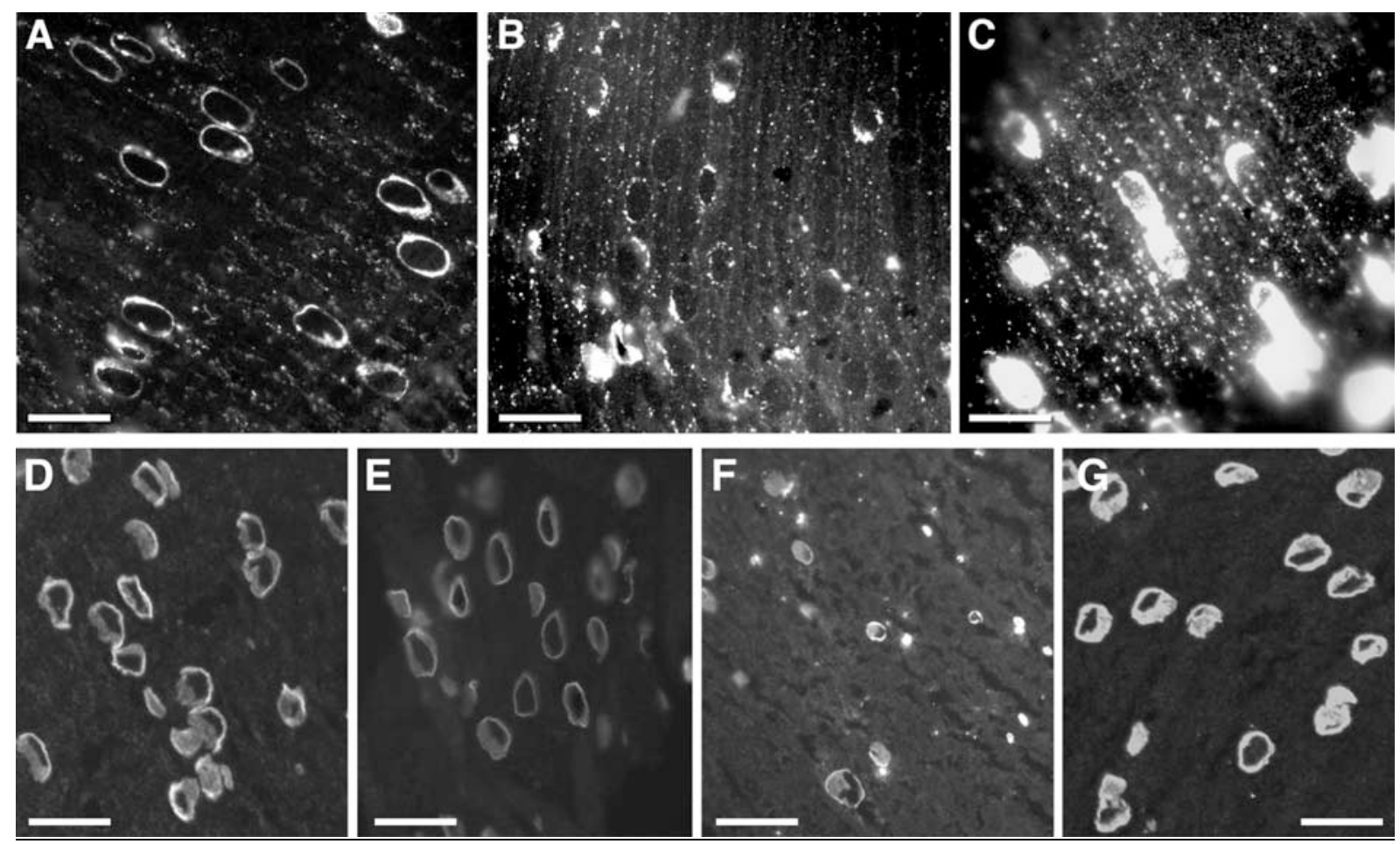

\section{Figure 6}

CLSM of cryo-sections of the bow zone labeled with anti-KDEL antibody. A : wild-type, B : Cx46 -/- and C : Cx50 -/- lenses. Bars $=20 \mu \mathrm{m}$

Cryo-sections labeled with anti-Lamin A/C antibody. D : wild-type, $\mathbf{E}$ and $\mathbf{F}: \mathrm{Cx} 46-/-$, X G : Cx $50-/$ - lenses. Bars $=25 \mu \mathrm{m}$ 

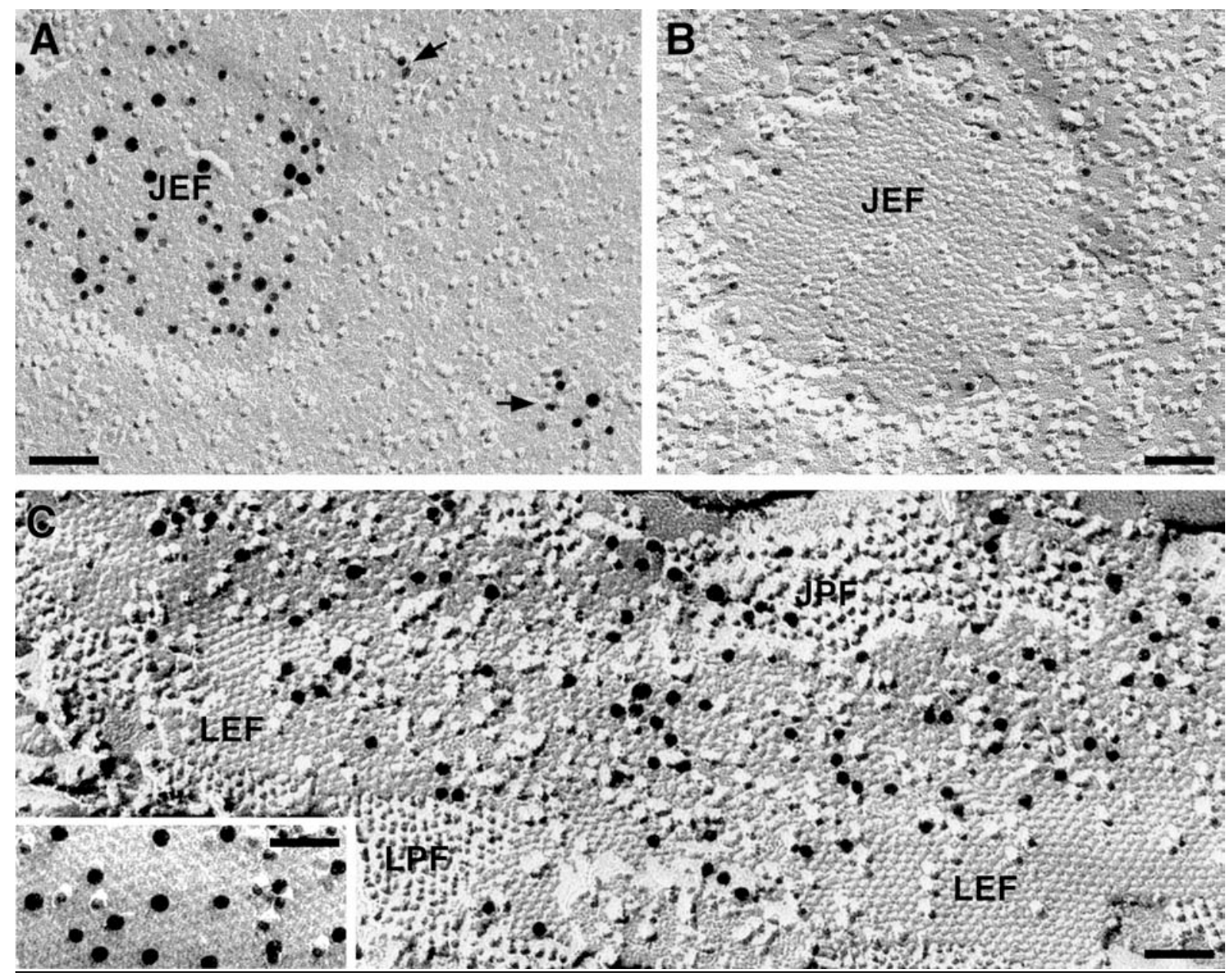

Figure 7

FL of DF and MF-NF from wild-type lens.

A : Double immunolabeling of DF junctional plaque using anti-Cx46 (15 nm gold particles) and anti-Cx50 (10 nm gold particles) antibodies. Arrows point to groups of small clusters of $9 \mathrm{~nm} \mathrm{IMP,} \mathrm{labeled} \mathrm{by} \mathrm{the} \mathrm{two} \mathrm{anti-}$ connexin antibodies. Junctional EF (JEF).

Bar $=75 \mathrm{~nm}$

B :FL of DF junctional plaque using anti-MP26 (10 nm gold particles) antibody. The gold particles circumscribe the junctional plaque. Junctional EF (JEF).

$\mathrm{Bar}=65 \mathrm{~nm}$

C : FL of MF-NF. Double immunolabeling using anti-Cx46 (15 nm gold particles) and anti-Cx50 (10 nm gold particles) antibodies, showing a large area where 7-8 nm particles on PF (LPF) and pits on EF (LEF) form geometrically-packed arrays (lattice domain). Note that in some other areas (JPF) IMP of $9 \mathrm{~nm}$-diameter, are randonmly distributed.

Bar $=50 \mathrm{~nm}$

Inset: The lattice domain was immunolabeled using anti-MP26 (10 nm gold particles) antibody.

Bar $=40 \mathrm{~nm}$ 


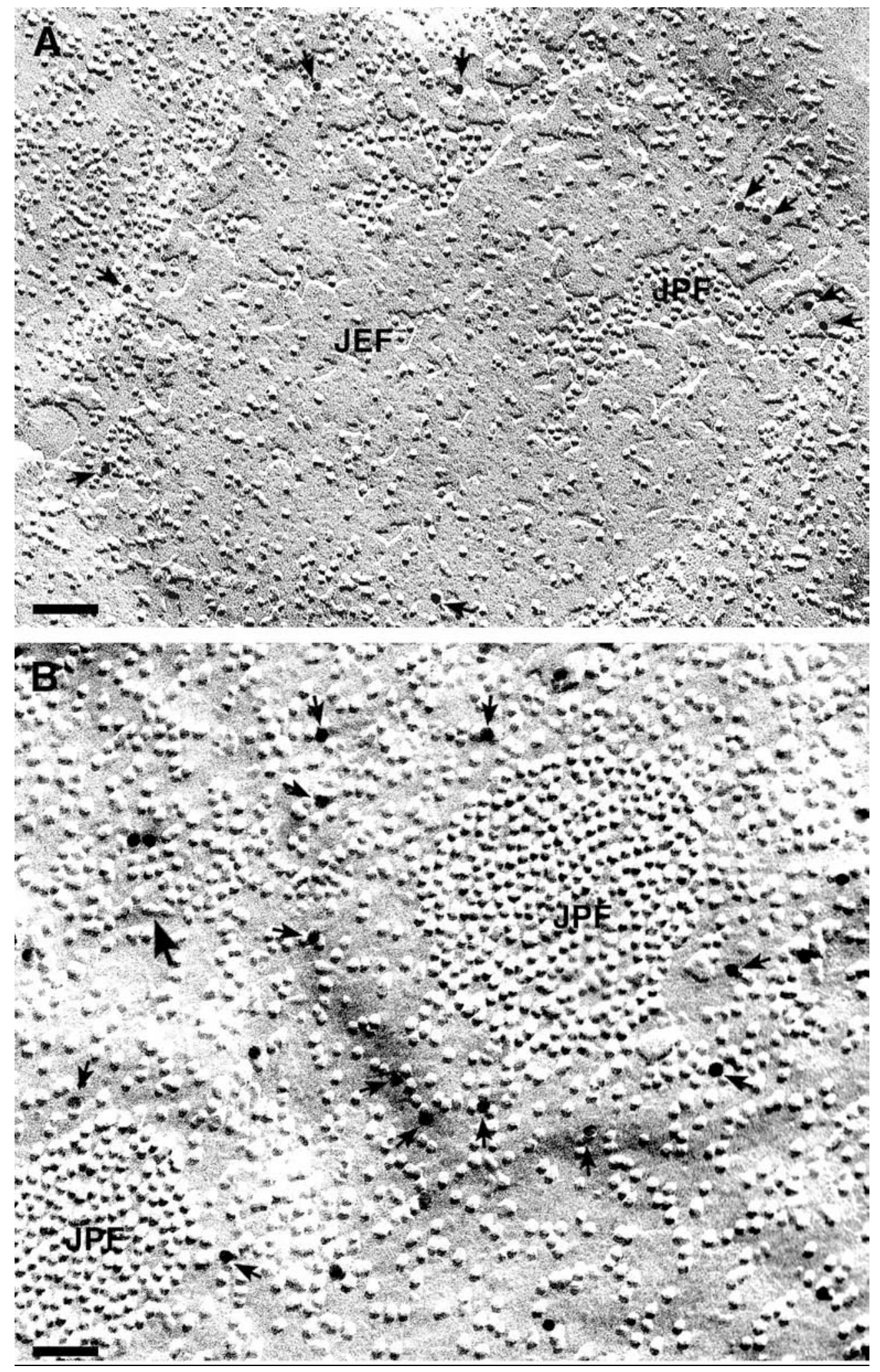

\section{Figure 8}

FL of DF from Cx46 -/- lens immunogold-labeled with anti-MP26 antibody.

A: A large junctional plaque is encircled (arrows) by gold particles $(10 \mathrm{~nm})$. Bar $=80 \mathrm{~nm}$

B : PF of DF membrane area where $9 \mathrm{~nm}$ IMP form either rows (larger arrow) or junctional plaques (JPF). Small arrows point to immunogold-labeled MP26 distributed around the junctional domains. Bar $=50 \mathrm{~nm}$ 

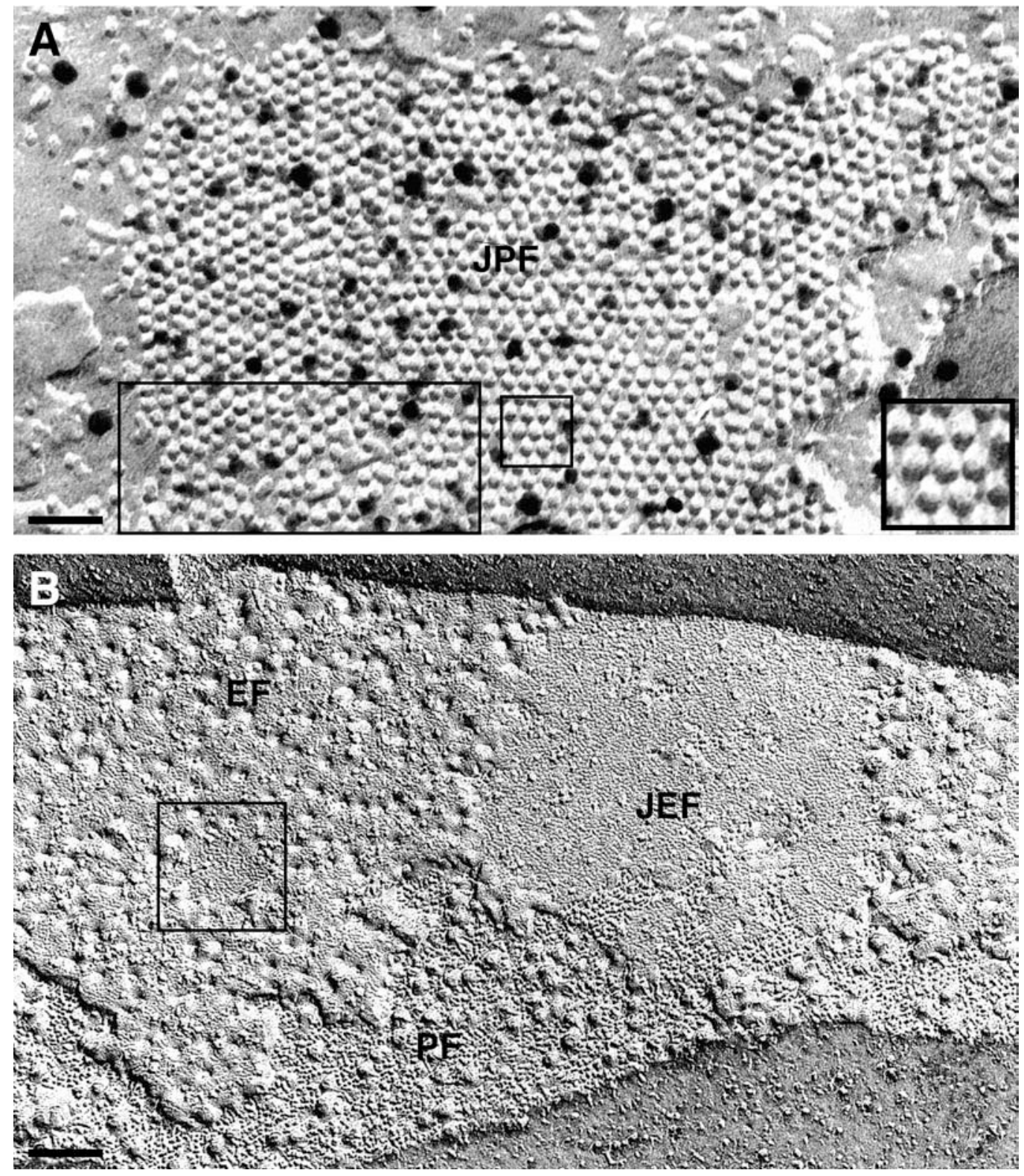

\section{Figure 9}

A : FL of DF from Cx 46 -/- lens. Double immunolabeling using anti-Cx50 (10 nm gold particles) and anti-MP26 (15 nm gold particles). Immunogold-labeled MP26 is distributed around the junctional plaque but also appear co-distributed with immunogold-labeled Cx50 in the junctional domain (JPF). This junctional plaque displays either randomly distributed $9 \mathrm{~nm}$ IMP (outlined in a rectangle), or geometrically-packed arrays of particles center-to-center distance of 7-8 $\mathrm{nm}$. The inset represent high magnification of a selected area (square) showing the hexagonal pattern of IMP.

Bar $=45 \mathrm{~nm}$

B: FF of DF from Cx46 -/- lens treated with filipin. A large junctional domain is surrounded by the filipininduced lesions (FIL). A small junctional plaque (square) is excluded from FIL.

Bar $=90 \mathrm{~nm}$ 



\section{Figure 10}

A : FF of MF-NF from Cx46 -/- lens showing an entire plasma membrane segment occupied by a geometrical lattice of 7-8 nm IMP, LPF (lattice, protoplasmic fracture face) and pits on LEF (lattice, external fracture face). Bar $=200 \mathrm{~nm}$

B: FL of MF-NF from Cx46 -/- lens. The lattice of geometrically-packed 7-8 nm particles is intensely labeled using anti-Cx50 (10 nm gold particles) and anti-MP26 (15 nm gold particles) antibodies.

Bar $=45 \mathrm{~nm}$

C: Thin section of MF-NF from Cx46 -/- lens. The pentalaminar membrane profile (10-11 nm thick) shows segments where globular subunits can be detected (arrows).

$\mathrm{Bar}=50 \mathrm{~nm}$

D: $\mathrm{FF}$ of MF-NF from $\mathrm{Cx} 46 \%$ lens treated with filipin. The lattice domain is segregated from membrane areas where FIL are concentrated.

$\mathrm{Bar}=75 \mathrm{~nm}$ 

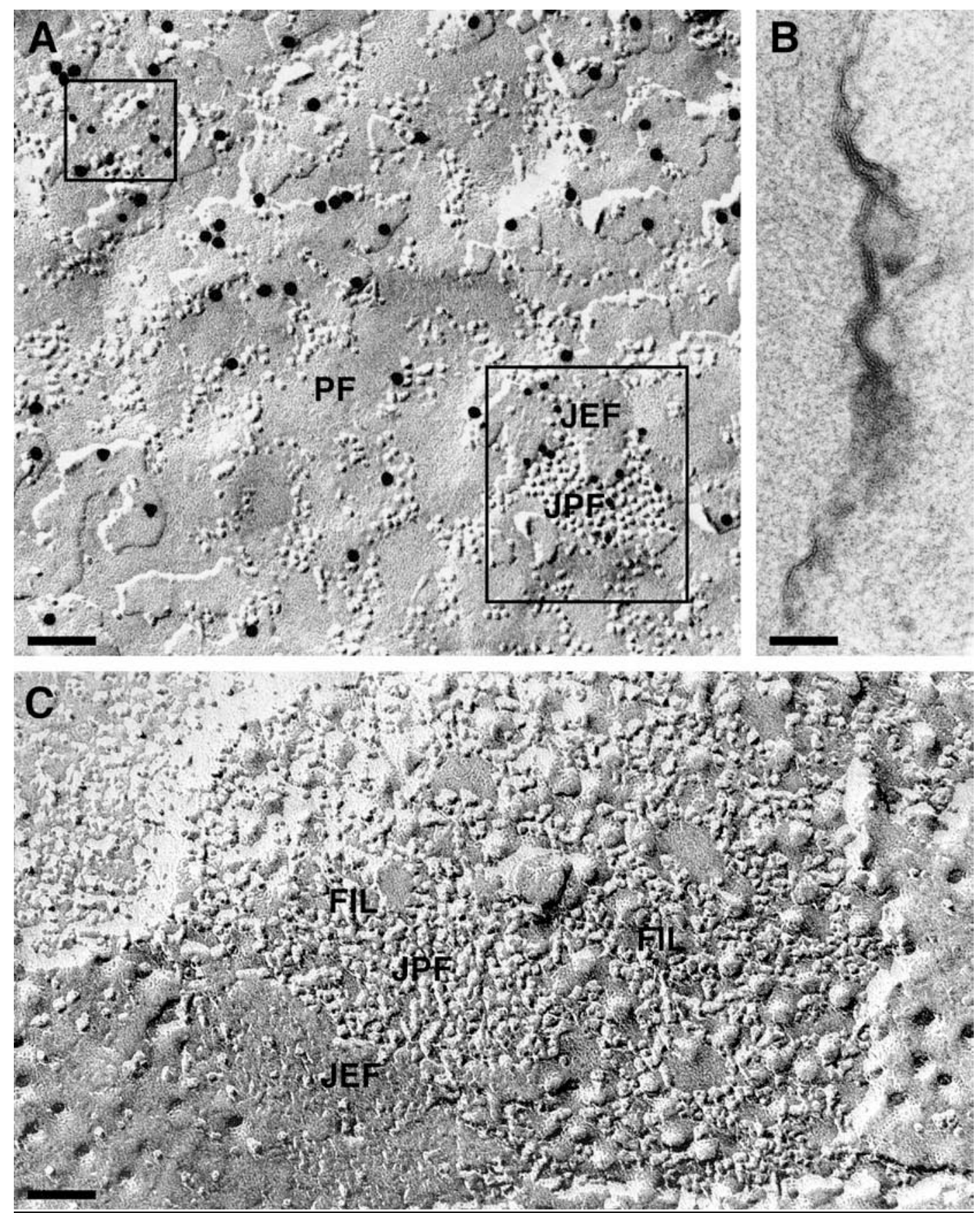

\section{Figure 11}

A: FL of DF from Cx50 -/- lens. Double immunolabeling using anti-Cx46 (10 nm gold particles) and anti-MP26 (15 nm gold particles) antibodies. Small junctional plaques are immunogold-labeled with anti-Cx46 antibody (outlined by a square and a rectangle). Immunogold-labeled MP26 appears randomly distributed.

Bar $=75 \mathrm{~nm}$

B: : Thin section of Cx50 -/- junctional domain between differentiating fiber cells, showing a distorted pentalaminar profile of variable thickness ranging between $9-10 \mathrm{~nm}$.

Bar $=80 \mathrm{~nm}$

C: FF of Cx50 -/- DF treated with filipin. Filipin induced lesions (FIL) represented by bumps and pits of various dimensions are localized in close proximity or within the junctional domain. Bar $=80 \mathrm{~nm}$ 


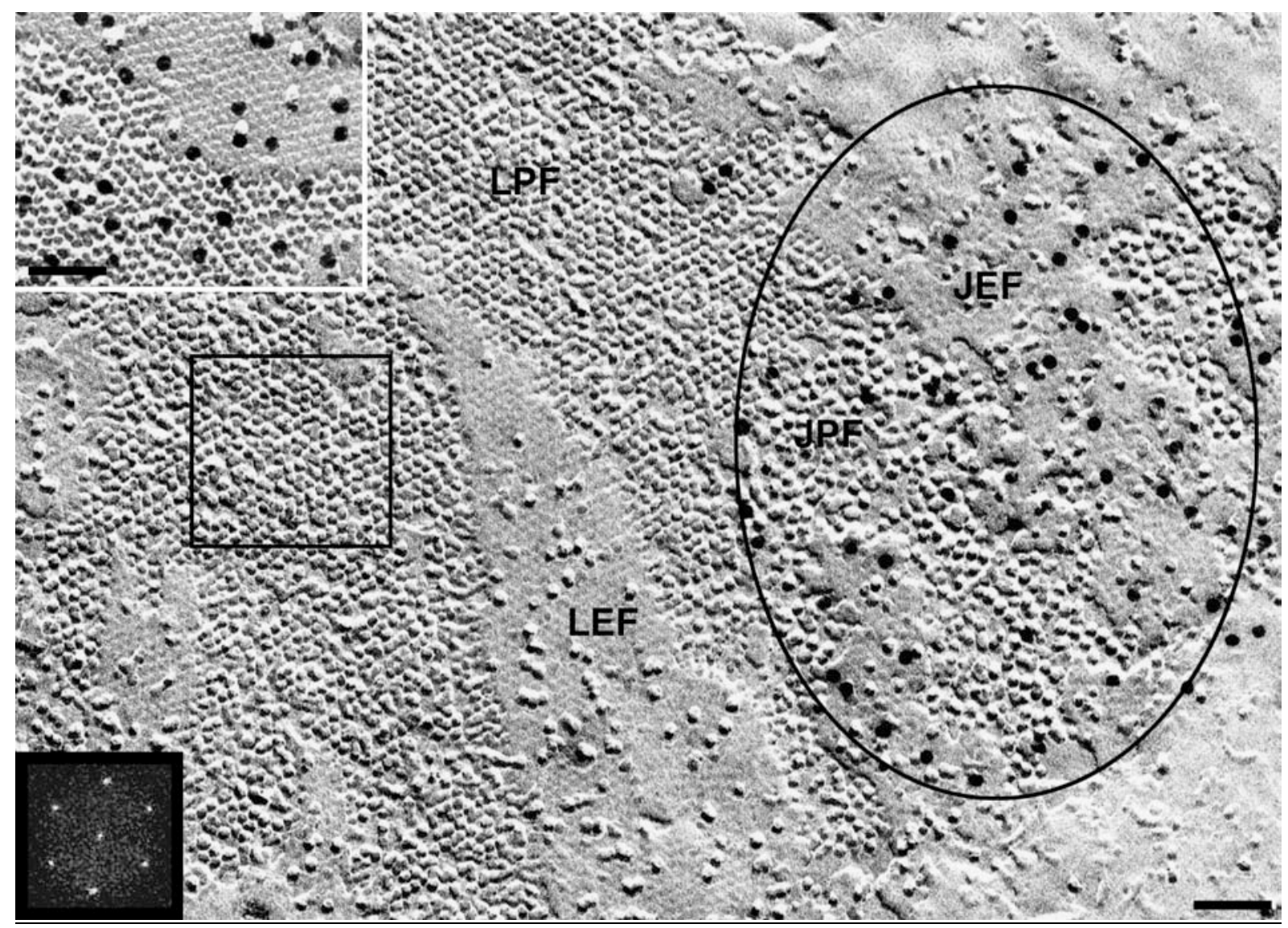

\section{Figure 12}

FL of Cx50 -/- MF-NF. The junctional domain (JPF and JEF) is characterized by randomly assembled $9 \mathrm{~nm}$ IMP immunogold-labeled by anti-Cx46 antibody (outlined in the circle). The junctional domain is excluded from the geometrical lattice of repeating subunits (7-8 nm diameter) on PF (LPF) and pits on EF (LEF). In the inset, at the upper left corner, is shown that the lattice domain is immunogold-labeled by anti-MP26 antibody. In the inset, at the low left corner, is shown the computer-generated optical diffraction pattern of the lattice domain outlined in a square. This pattern shows a prevailing hexagonal symmetry.

Bar $=50 \mathrm{~nm}$ 


\section{Figure 13}

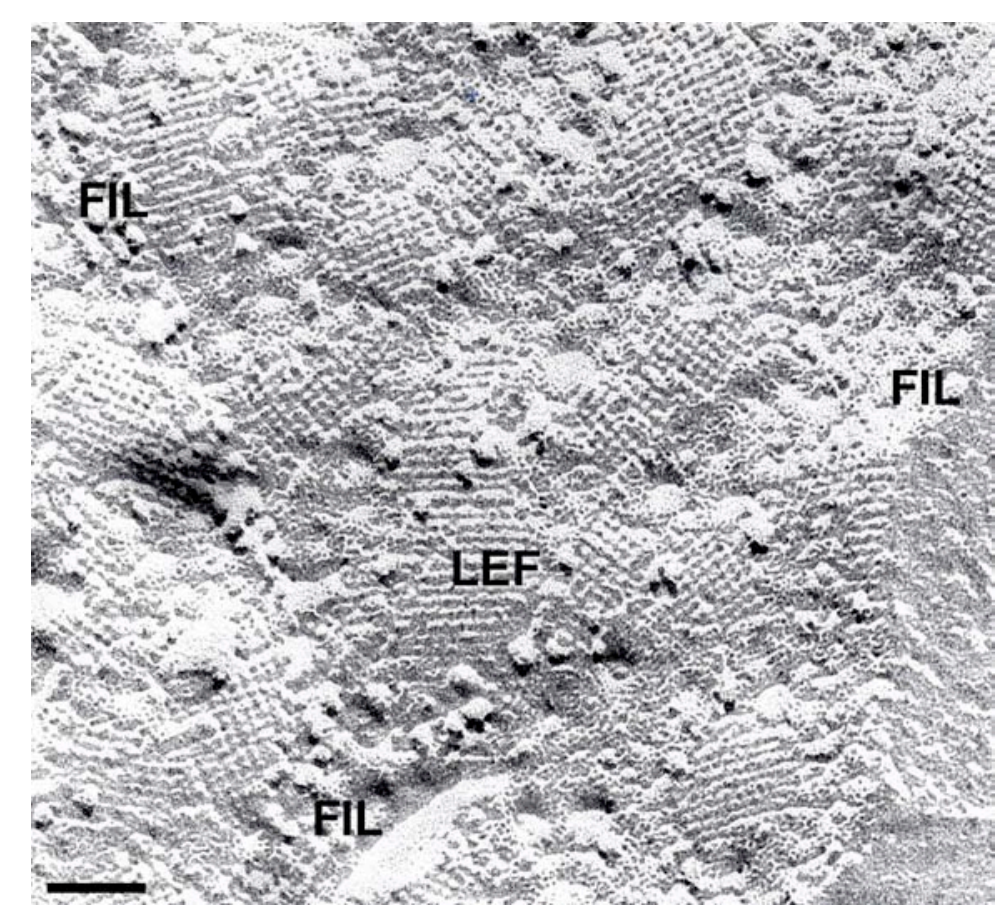

FF of Cx50 -/- MF-NF treated with filipin. The FIL are localized in membrane areas (arrows) excluded from the lattice domain (LEF).

Bar $=75 \mathrm{~nm}$ 